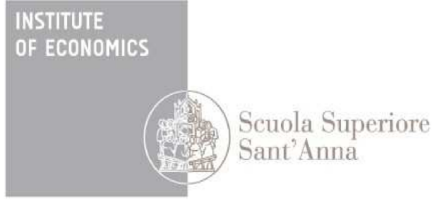

LEM | Laboratory of Economics and Management

Institute of Economics

Scuola Superiore Sant'Anna

Piazza Martiri della Libertà, 33 - 56127 Pisa, Italy ph. +3905088.33 .43$

institute.economics@sssup.it

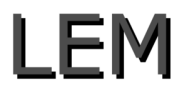

Working Paper Series

\title{
Post-Mortem Examination of the International Financial Network
}

\author{
Matteo Chinazzi o \\ Giorgio Fagiolo o \\ Javier A. Reyes ${ }^{\S}$ \\ Stefano Schiavo * \\ - Scuola Superiore Sant'Anna, Pisa, Italy \\ ${ }^{5}$ University of Arkansas, USA \\ * University of Trento, Italy; and OFCE, France
}




\title{
Post-Mortem Examination of the International Financial Network
}

\author{
Matteo Chinazzi* Giorgio Fagiolo ${ }^{\dagger} \quad$ Javier A. Reyes ${ }^{\ddagger} \quad$ Stefano Schiavo ${ }^{\S}$
}

January 30, 2012

\begin{abstract}
As the recent crisis has forcefully suggested, understanding financial-market interconnectedness is of a paramount importance to explain systemic risk, stability and economic dynamics. In this paper, we address these issues along two related perspectives. First, we explore the statistical properties of the International Financial Network (IFN), defined as the weighted-directed multigraph where nodes are world countries and links represent debtor-creditor relationships in equities and short/long-run debt. We investigate whether the 2008 financial crisis has resulted in a significant change in the topological properties of the IFN. Our findings suggest that the crisis caused not only a reduction in the amount of securities traded, but also induced changes in the topology of the network and in the time evolution of its statistical properties. This has happened, however, without changing the disassortative, core-periphery structure of the IFN architecture. Second, we perform an econometric study to examine the ability of network-based measures to explain crosscountry differences in crisis intensity. We investigate whether the conclusion of previous studies showing that international connectedness is not a relevant predictor of crisis intensity may be reversed, once one explicitly accounts for the position of each country within the IFN. We show that higher interconnectedness reduces the severity of the crisis, as it allows adverse shocks to dissipate quicker. However, the systemic risk hypothesis cannot be completely dismissed and being central in the network, if the node is not a member of a rich club, puts the country in an adverse and risky position in times of crises. Finally, we find strong evidence of nonlinear effects, once the high degree of heterogeneity that characterizes the IFN is taken into account.
\end{abstract}

Keywords: financial networks, crisis, early warning systems.

JEL classification: E65, F30, G01

The authors blame each other for any remaining mistake. They nevertheless agree on the need to acknowledge insightful comments from participants to the Research Conference on Financial Networks (Geneva, June 2011), ECCS'11 (Vienna, September 2011), and the REPLHA International Conference (Milan, October 2011).

*Sant'Anna School of Advanced Studies (Pisa) - Italy. E-mail: matteo.chinazzi@gmail.com

†Sant'Anna School of Advanced Studies (Pisa) - Italy. E-mail: giorgio.fagiolo@sssup.it

$\ddagger$ University of Arkansas - USA. E-mail: JReyes@walton.uark.edu

$\S$ University of Trento - Italy, and OFCE - France. E-mail: stefano.schiavo@unitn.it 


\section{Introduction}

The recent financial crisis has forcefully highlighted the potential problems arising from financial market interconnectedness. From a microeconomic point of view, one of the main reasons behind the bailout of Bear Stearns, orchestrated by the Federal Reserve in March 2008, was that the bank was too connected to be allowed to fail. From a macroeconomic perspective, financial integration has allowed problems originated in a relatively small segment of the U.S. credit market to diffuse rapidly and pose a serious threat to the overall stability of the world economy (Battiston et al., 2011). As stated by Schweitzer et al. (2009), the crisis calls for a better understanding of the structure and evolution of economic networks, defined as systems where individual players (agents, banks, countries,...) do not act in isolation but rather are linked via a complex set of interactions.

Along these lines, even before the eruption of the crisis, several authors had started studying contagion effects in the inter-bank lending network. ${ }^{1}$ For example, Allen and Gale (2000), which is often regarded as one of the seminal contributions of this literature, find that shocks are more easily dissipated within complete networks (where all possible bilateral links exists), whereas incomplete networks tend to be less robust. A similar conclusion is reached by Freixas et al. (2000) and Leitner (2005). Furthermore, Gai and Kapadia (2010) employ tools borrowed from the epidemiological literature to show that greater connectivity reduces the likelihood of widespread default, but also that dense financial networks display the tendency to be "robustyet-fragile": the probability of contagion is typically low, but when it happens its effects will be widespread and difficult to isolate. The possible emergence of contagion depends crucially on the degree of heterogeneity, which can refer either to node intrinsic characteristics (such as size, see Iori et al., 2006) or to node connectivity (Caccioli et al., 2011). Indeed, when the network is not homogeneous the positive effect of higher density on diversification is counterbalanced by the fragility associated with the presence of very central (and therefore critical) players. The existence of extreme behaviors and tipping points is forcefully argued by Haldane and May (2011), who claim an interdisciplinary network perspective can bring new and useful insights into financial research, especially in the realms of regulation and stability.

From the empirical point of view, greater availability of data has led many researchers

\footnotetext{
${ }^{1}$ A concise yet very good overview of the literature on financial networks is provided by Allen and Babus (2009).
} 
to investigate the structural properties of domestic (e.g. Cocco et al., 2009) and cross-border interbank networks (e.g. von Peter, 2007). Recently, Hale (2011) has built a global banking network of almost 8,000 large institutions in 141 countries, and found that link formation slows down during global financial crises.

In this paper we focus on the country, rather than bank level (in a way simlar to Schiavo et al., 2010; Minoiu and Reyes, 2011), and we provide evidence on how the topology of their financial relationships can help us understand what happened after the financial shocks of 2008. We define the International Financial Network (IFN) as a macro weighted-directed (multi) graph where nodes are countries joined by weighted-directed links that connect the issuing country to the holder of the security (possibly disaggregated by type). That is, we have an outgoing link starting from the issuing country (debtor) and reaching the holding country (creditor) as shown in Figure 1. By taking a network perspective to the study of the financial crisis, we assess the impact of the crisis on the topological properties of the IFN, and we show how network indicators can help explaining cross-country differences in the severity of the crisis.

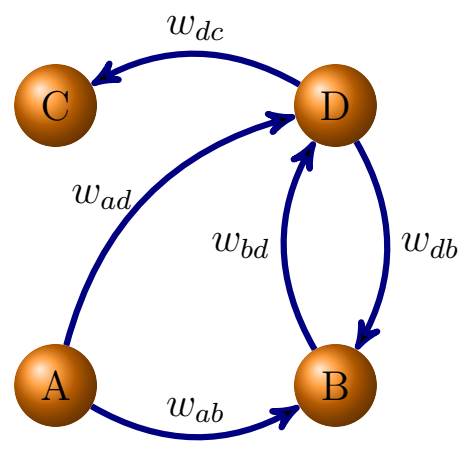

Figure 1: International Financial Network (IFN): a macro weighted-directed graph where nodes are countries joined by directed links. Links connect issuing country to security holder. For example, $A$ issues securities held by $B$ and $D$ (i.e. $A$ is a debtor of $B$ and $D$ ) where $w_{a b}$ and $w_{a d}$ are the values of such securities in (millions of) current dollars.

With respect to this last point, the paper refers to the whole literature that has flourished in the last couple of years, aiming at explaining the cross-sectional difference in crisis intensity (see Berkmen et al., 2009; Blanchard et al., 2010; Claessens et al., 2010; Rose and Spiegel, 2010, 2011; Frankel and Saravelos, 2011; Lane and Milesi-Ferretti, 2011; Giannone et al., 2011, to quote just a few). In turn, this is part of a broader effort targeted at establishing an Early Warning System (EWS) capable of signaling the building up of system risk in international financial markets, mainly at the country level. Different official sources have called for engineering effective EWSs: 
for instance, the Final Communiqué of the April 2009 G-20 Summit held in London states

"we agree ... that the FSB [Financial Stability Board] should collaborate with the IMF to provide early warning of macroeconomic and financial risks and the actions needed to address them".

So far, the many attempts made by different authors have focused on crisis intensity, not its timing, as the latter is much more difficult to forecast. Although different methodologies have been adopted, many works are based on simple cross-country OLS regressions of (one or more) crisis measures on macroeconomic and financial indicators (lagged, to correct for possible endogeneity). The goal of the various empirical exercises is to identify a set of variables that can effectively explain the difference in the intensity of the crisis faced by each country.

Despite a large effort (more than 100 candidate explanatory variables are tested by Rose and Spiegel, 2010, alone), this stream of literature has not been very successful in identifying a robust set of covariates associated with the severity of the crisis (Rose and Spiegel, 2011). The way the crisis is defined and measured, the specific time-window analyzed, the number of explanatory variables used, all affect the results to a certain extent, although the bottom line remains roughly the same.

Two points are worth noting here. First, data availability imposes serious limitations to the number of data points in the analysis. Hence, a possible explanation for the lack of robust results is simply the small sample size (very often ranging between 50 and 80 observations), a problem for which there is no clear remedy. Second, one of the most striking (negative) results is, in our own view, the failure to identify international linkages (both in real and financial terms) between each country and the U.S. (the candidate epicenter of the crisis) as a meaningful predictor of crisis intensity. The evidence for an 'international channel' is weak at best, which is counterintuitive given the strong prior on the role of interconnectedness shared by many scholars and policymakers.

This paper aims at contributing to the the foregoing debate in at least two ways. First, we present a description of the main structural features of the IFN and their evolution over time. Furthermore, we carefully investigate whether the 2008 financial crisis has resulted in a significant change in the topological properties of the IFN. Second, given the systemic nature of the crisis and the recognition that high interconnectedness among financial intermediaries has 
played a major role in spreading the crisis, we examine the ability of network-based measures to improve the predictive power of EWS. In particular, we investigate whether international connectedness is a relevant predictor of crisis intensity when we not only consider bilateral flows, but we also look at the positions of each country within the IFN.

The rest of the paper is organized as follows. Section 2 describes the data and networkrelated methodology. A network analysis of the main structural features of the international financial network (IFN) and their evolution over time is presented in Section 3. Particular attention will be devoted to assess the impact of the 2008 crisis on the topological properties of the network. Section 4 investigates whether augmenting standard models with network-based measures enhances the predictive ability of EWS. This is done using both cross-sectional and panel techniques. Finally, Section 5 concludes.

\section{Data and Network Statistics}

The main source of data we employ in our analysis is the Coordinated Portfolio Investment Survey (CPIS), collected by the International Monetary Found (IMF). ${ }^{2}$ Data include crossborder portfolio investment holdings of equity securities, long-term debt securities and shortterm debt securities listed by country of residence of issuer. Overall, we have complete bilateral data for roughly 70 countries for the period 2001-2010.

We analyze the topology of the IFN in five different cases: when the graph is built considering all financial investments (Total Portfolio Investments, TPI); when we consider only equity securities (ES); debt securities (TDS); long-term debt securities (LTDS) and short-term debt securities (STDS). More formally, we build a 5-layer weighted-directed multigraph, where each directed link is weighted by the value of security - in millions of current dollars - issued by the origin node and held by the target, see Figure 2. Since we are also interested in assessing unweighted relations, we explore the properties of the binary projection of the weighted multigraph, where each directed link is present if the original weight is positive and does not exist otherwise.

The data allow us to describe the topological structure of the IFN along the lines of Schiavo et al. (2010), and track its evolution over time. Particular care is put in testing the hypothesis

\footnotetext{
${ }^{2}$ Data are documented and available at http://cpis.imf.org/ (last access January 2012).
} 
that the financial crisis results in a significant change in the structure of the IFN. To this extent, we focus on both aggregate and node-specific network statistics (see appendices $\mathrm{A}-\mathrm{C}$ for more formal definitions).

Aggregate statistics give information on the overall properties of the network. We study network density (i.e. the fraction of all possible links that are actually present) and two measures of asymmetry. These are useful to understand the probability that any outgoing link (with a given weight) is reciprocated (with a similar weight). A network would be fully symmetric if all links are reciprocated with the same weight. A higher asymmetry imply larger link unbalances in bilateral interactions. The two indexes of asymmetry are: a measure of absolute asymmetry (as in Fagiolo, 2006), where we treat all link unbalances as the same; a measure of relative asymmetry, where the average is taken over the individual relative-unbalance averages (as described in Appendix A).

Node-specific network statistics, instead, allow us to look at individual countries' positions within the IFN. That is, we can asses: how many financial counter-parties a country has (i.e. node degree measures), how much a country is exposed (i.e. node strength measures), how much connected and exposed are its neighbors (i.e. average nearest neighbor degree and strength measures), how much communal are relationship patterns between countries (i.e. node clustering measures) and how central are individual nodes within the IFN (i.e. centrality measures). The indicators we use allow us to understand not only how strongly a country is connected with its neighbors, but also the characteristics of the financial partners with which it decides to trade with. We analyze the web of financial relationships not only by checking the presence and the directionality of linkages, but also by providing different versions of the indicators to consider the intensity of the exchanges. Furthermore, by assessing the centrality of countries, we also detect which countries are primary sources of investments within the IFN (i.e. financial authorities) and which ones are primary borrowers (i.e. financial hubs). The detailed descriptions of the indicators used along with their economic interpretations are listed in Appendices B and C.

In addition, we study how node-specific network statistics correlate and how such correlation patterns evolve across the years. By doing so, we can assess whether the investing behavior of countries has been modified by the 2008 financial crisis. 


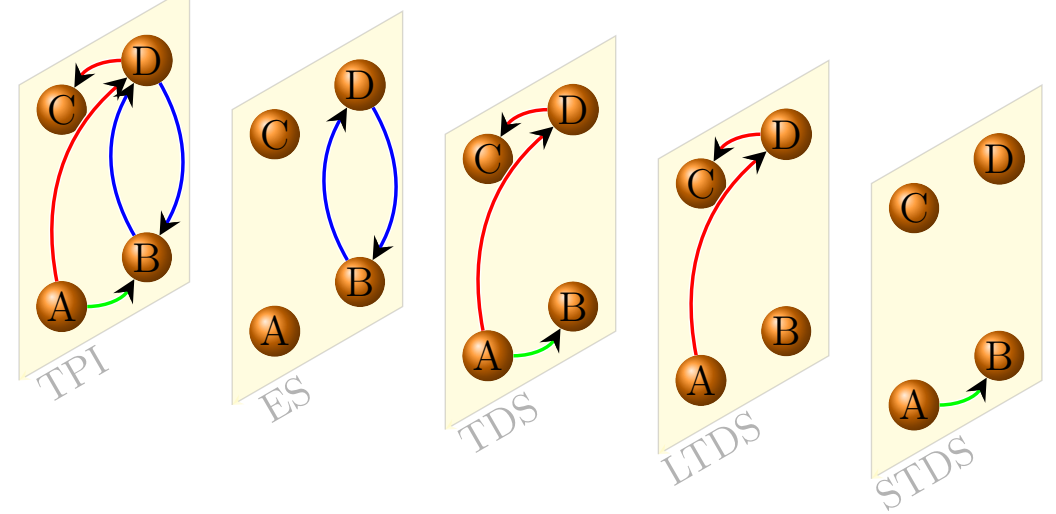

Figure 2: International Financial Network Layer Structure: five different layers are analyzed. Total Portfolio Investments (TPI): when the graph is built considering of all the financial exposures between countries. Equity Securities (ES): when we consider only equity securities. Total Debt Securities (TDS): when we consider all debt securities. Long-term Debt Securities (LTDS): when we consider only long-term debt securities. Short-term Debt Securities (STDS): when we consider only short-term debt securities.

\section{Evolution of the IFN: Pre and Post-Crisis Evidence}

Aggregate Network Statistics We begin by investigating the time evolution of aggregatenetwork statistics. Figure 3a shows that the density of TPI has always been increasing over the years with the only exception of 2008. Indeed, we observe a spike in network density between 2006 and 2007 and then a sudden drop in 2008. This means that the financial crisis caused some countries to revise their relationships with their partners, reducing the number of countries with which they had financial linkages (a result in line with Hale, 2011).

Network asymmetry seems to be generally constant when we consider only the presence or absence of financial linkages, both in the absolute and in the relative case (see Figures $3 \mathrm{c}, 3 \mathrm{e})$. Instead, when we take into account also the intensity of the financial relationships, the behavior is less straightforward. If we look at the absolute weighted network asymmetry index (see Figure 3d) we observe that in terms of debt securities, the asymmetry is decreasing up to years $2005 / 2006$, while it is increasing starting from 2007; in terms of equity securities, the asymmetry is increasing up to year 2007 and decreasing thereafter. Instead, when we look at the relative weighted asymmetry index, we find that asymmetry has been steadily increasing over the entire period, even though the rate of growth seems not to be particularly fast. Overall, this suggests that widespread relative unbalances might have driven the network to be levelasymmetric after 2007. 
Node-specific Network Statistics In order to get a more fine understanding of the evolution of IFN topological properties over time, we now turn to analyzing node-specific network measures. First, note that the shape of the distribution of the number of financial relationships among the countries changes over the years. Overall, we observe that node-degree distributions are bimodal for TPI and ES while they are closer to unimodality for $T D S$, even though they exhibit a very long right tail (see Figure 4) However, if we separately observe the behavior of node in-degree and node out-degree, we see that the distributions for the latter statistics are often closer to unimodality than the ones for in-degree. Furthermore, bimodality is more pronounced and increasing in the period 2001-2007, whereas it appears to be less severe in the years after 2008. All this may suggest a sort of "reversion to the mean" movement, operated by the nodes that were lying on the right tail of the distribution. This shift is most evident in the $E S$ layer, since equity securities react more rapidly to changes on the financial markets. In general, we also observe a movement of the distribution to the right, up to 2007, while there is some settle back in the period 2008-2010. Overall, this means that the financial crisis not only changed the topology of the network by decreasing the overall number of connections among the countries (see the above evidence on density), but also by altering the distributions of such relationships. Very connected nodes seem to have reduced their exposures. This is especially true for nodes that had many creditors compared to average behavior of all other countries.

The mean value of average nearest-neighbor degree $(A N N D$, see Figure 5$)$ is instead increasing in the period before the financial crisis, it drops in 2008, it increases again in 2009, then it remains almost constant in 2010. On the other hand, ANND standard deviation is generally decreasing over time: countries link to more and more connected neighbors, i.e. ANND distributions are shifting towards the right over time. This may mean that negative shocks can be absorbed more easily since their impact is shared by many countries. It also suggests that extreme shocks can diffuse more easily throughout the network (Gai and Kapadia, 2010).

Turning to clustering coefficients, we observe that average binary clustering (i.e. $B C C$ ) is increasing over time in the TPI layer (see Figure 6). Actually, the entire distribution shifts towards the right over the years, with the exception of 2008. This behavior seems to be driven by the equity-security layer. Debt-security layers exhibit an increase in average $B C C$ up to 2007, but then the distributions start moving towards the left until 2010. In other words, 
equity securities recovered more quickly from the 2008 shock, whereas investment behavior in debt securities have been strongly impacted by the crisis. A decrease in clustering coefficients suggests indeed that each country is contracting debt or credit relationships with countries that have less probability (compared to the past) of being financial partners among themselves. We observe a similar behavior also when we look at weighted clustering coefficients, the only difference being that now, in the debt layers, some recovery seems to be present in 2010 (that is, the movement towards the left seems to have come to an end).

The same evidence is also observed in many other network statistics, like (in and out) node strength, average-nearest neighbor strength and weighted clustering. This suggests that the ES layer is the quicker to recover, while relationships based on debt securities seem to require more time to invert their decreasing trend after the crisis.

Combining together these different findings we can get a glimpse of what is happening to the IFN after the financial crisis. In particular, it seems that the huge shock of 2008 caused not only a reduction in the amount of securities traded, but also induced changes in the topology of the network and in the time evolution of its patterns. Countries reduced the number of their financial partners, especially in terms of number of debtors. That is, creditors with many debtors reduced the number of their counterparts and seemed to have adopted a more careful selection of their investing opportunities. In 2010, however, this effect was already over. More generally, in 2007 and 2008 we observed a drop in network density and an increase in asymmetry, which can be interpreted as a symptom of the riskiness and uncertainty that was perceived by markets in those years. We have also observed that big creditors decided to adopt less risky strategies, as exemplified by the movements back towards the mean of node in-strength. Furthermore, core countries appeared to have reduced their exposures towards network periphery: the left tail of the node out-strength (in logs) seems to have flattened after 2007. A number of countries were no longer able to issue large amounts of securities, probably because they could not manage to find creditors willing to support them.

Correlations between Network Statistics In general, one is not only interested in assessing how the moments of the distribution of node statistics change over time, but also the evolution of their correlation structure, which is the issue we focus on in this subsection.

In 2001-2010, we observe high and positive correlation between node degree and node 
strength (see Figure 7a). This implies that countries with a large number of creditors/debtors tend also to hold/issue more dollars of securities. By breaking down the correlation even further we observe that: the correlation between NDin and NSin is generally increasing over time (with the exception of year 2008), while the correlation between NDout and NSout is generally decreasing over time (even though both measures remain strongly positive). This means that countries who have more debtors tend to increase the amount of dollars of securities they hold; while countries that have more creditors tend to diminish their exposures.

Instead, correlations between node degree/strength and node $A N N D / A N N S$ are both high and negative (see Figures 7b,7c). In line with previous research (Schiavo et al., 2010), we therefore find that the network is very disassortative: neighbors of well connected and highly influential countries have fewer creditors/debtors and hold/issue less securities. In particular, we note that the binary disassortativity seems to have remained roughly constant over time. Conversely, weighted disassortativity has been reducing after 2005 and node strength/ANNS correlation appears to be increasing in the last four years of our sample. Hence, during the crisis, when it comes to counting the number of relationships of the nodes, well connected countries tended to preferentially engage in relationships with even more peripheral partners, whereas the result is the opposite if we look at the values of the securities issued or held by the parties.

Degree-clustering correlation is high and negative in the binary case over the whole period (see Figure 8a). Countries that are creditors/debtors of many countries interact with pairs of countries that are not typically debtors or creditors of each other and form a hub-and-spoke structure. However, the insight is the opposite if we look at the weighted case, where the correlation is between node strength and $W C C$ (see Figure 8b). Indeed, in this second case we find that correlation is high and positive meaning that countries which hold/issue a lot of dollars of securities typically interact with pair of countries that are themselves very tightly interconnected. Put it differently, when we look at the binary representation of the network, it appears that "clubs of countries" are not a relevant feature of our data, whereas once we look at the weighted IFN, we find evidence of (local) rich club behavior. This suggests that existing heterogeneity in link weights is a possible driver for the emergence of rich clubs.

Last, it is rather important to notice that there are no clear structural changes after 2007 
in terms of correlation structures. This means that the overall behavior of countries in the sample, was not that altered, at the macro level, by the financial crisis and that the patterns that were present before 2007-2008 have not been affected in a consistent manner. This is in line with previous results on the international trade network (Fagiolo et al., 2009) and hint to a strong robustness and resilience.

Rich Club Behavior As mentioned when discussing correlation patterns between node strength and $W C C$, rich-club effects seem to be locally present in the IFN. But what about rich-club evidence at the global level? To explore this issue, we have computed the rich-club coefficient $(R C C)$ as in Opsahl et al. (2008). This coefficient measures the fraction of weights shared among "rich nodes", as compared to the total amount they could have shared if they were connected only through the strongest links in the network. In our case, following Fagiolo et al. (2009), we chose total node strength as richness parameter. That is, we ranked all countries in terms of total value (dollars) of securities they held or issued in a given year, considering as richer those countries that have higher node strength.

To compare $R C C$ observed values with statistically reasonable benchmarks, one has to define a null model, i.e. a random network from which to compute expected correlation-free $R C C$ to be compared with the observed ones. In Appendix D we briefly describe the null models that we have employed for this exercise and in Appendix E we provide a formal definition of $R C C$.

Notice that, given any club size, a value larger than one for the $R C C$ implies evidence of rich-club behavior. As we can see from Figure 9, rich clubs do indeed globally emerge in the IFN and they typically include the top 25/30 countries. This result is consistent regardless the null model one employs as benchmark.Furthermore, it suggests that the IFN is characterized by a core-periphery structure, where the most strongly connected 25/30 countries are linked among themselves more than it would have been expected in models assuming the same first-order binary and weighted network statistics (in/out node degree and in/out node strength).

Network Centrality Given the rich-club structure found above, an interesting issue to explore concerns assessing financial centrality and influence in the IFN. To do that, we employ the HITS algorithm (Kleinberg, 1999) to compute hub-and-authority scores both in the binary and in the weighted case. They both measure the extent to which a node is central in the 
network, but look at different features: authorities (i.e. nodes with a high authority score) are nodes that are pointed-to (via strongly weighted in-links) by many hubs, whereas hubs are nodes that point (via strongly weighted out-links) to many authorities. In other words, authorities are nodes that contain useful information, whereas hubs are nodes that point where useful information is located. Of course an authoritative node may also be a hub, and vice versa. In the IFN, financial authorities are primary sources of investments (i.e. countries that hold securities of many countries), while financial hubs are primary borrowers (i.e. countries that issue securities held by many partners).

As we can see in Appendix F, a few interesting patterns emerge looking at the rankings of the top 30 countries in each of the four centrality measures. As far as binary hub-centrality is concerned, note that top ranks typically feature developed economies (e.g. United States, United Kingdom, France, Germany, Japan, ... ). However, other well-known financial centers also pop up as hubs. For example Luxembourg, Switzerland and Cayman Islands typically score in the top $10 / 15$ positions. Their presence is even more important when we look at the binary authority centrality: Luxembourg and Switzerland are constantly in the top 5. The U.S. and U.K., conversely, move a lot up and down in the ranking over the years: the former looses many positions over time, whereas the latter climbs the ranking up to the second place in four out of the last five years. Instead, when we look at weighted centrality measures, the likelihood that a country exhibits at the same time a large hub and authority score is larger than in the binary case.

The presence of many tax heavens among the top binary financial authorities can be explained by arguing that many companies around the world moved their fiscal residence to these countries for tax reasons. Therefore, many tax heavens are expected to be listed as important financial authorities. Another interesting finding is related to the opposite roles that Cayman Islands and Luxembourg play in the IFN. Cayman Islands are more important as a financial hub than as a financial authority. Luxembourg appears to be a financial authority but not a financial hub. This could indicate that the former is more important as a country where depositing money, while the latter is more useful to incorporate companies that then can be employed as holdings for companies operating elsewhere. 


\section{Econometric Analysis}

In this Section we investigate whether network measures contain useful information that can improve our understanding of cross-country differences in the severity of the recent financial crisis. We start from the baseline methodology employed in the literature on EWSs, namely cross-sectional (OLS) regression of one or more crisis measures on lagged macroeconomic and financial indicators. Therefore, we use this as a departure point for analysis but then move towards a more complete analysis that uses two-step GMM first difference panel estimation.

Since it is difficult to find a robust set of covariates, we select a small number of them based on previous results as well as by means of a preliminary analysis (not presented here in the interest of space). We need to focus on a small number of explanatory variables because the sample size is small and we therefore need to keep a reasonable number of degrees of freedom. Even for the GMM panel estimation, the set of explanatory variables is limited because the number of instruments constrain the estimation.

\subsection{Network Effects}

From the previous sections, it is clear that there are a number of network indicators that could be used for this type of analysis. At the beginning, in the cross-section exercise, we opt for using only six indicators that have a clearer and perhaps more intuitive interpretation, albeit we will expand the analysis introducing more network measures during the GMM exercise. To begin with we use the number of creditors and debtors of each country (NDin and NDout) which allow us to look at first-degree of separation effects. These indicators can be related, intuitively, to portfolio returns maximization and risk diversification, since these efforts would lead to lending/borrowing from different sources, although the effects of aggregate connectivity resulting from these efforts could also lead to a higher vulnerability. The four different options for the average nearest neighbor degree $(A N N D)$ extend the analysis to second-order effects in that they describe different types/characteristics of "lending/credit chains":

1. The average number of debtors of country $i$ 's creditors (ANND_outin)

2. The average number of debtors of country $i$ 's debtors $\left(A N N D_{-}\right.$inin $)$

3. The average number of creditors of country $i$ 's debtors (ANND_inout). 
4. The average number of creditors of country $i$ 's creditors (ANND_outout)

For example, as described in Calvo (1998), a given country $i$ can face "capital sudden stops" because other countries, which borrow from the same creditors, default on their debt. This jeopardizes the probability that the country in question can successfully refinance its debt, although it may be financially sound. It has to be emphasized that this would be the interpretation from the systemic risk perspective. From the point of view of risk diversification, it can be argued that the more debtors that country $i^{\prime} s$ creditors have, the less likely is that a shock from a given country could affect the strong and diversified portfolio of country $i^{\prime} s$ creditors. Similar interpretations can be articulated for each of the ANND versions considered here, where a larger number of creditors or debtors can be seen as a stronger and more resilient credit/lending chain but introduces also more interdependency. In the end whether markets/investors interpret the observed interdependencies as positive (risk diversification) or negative (systemic risk), or with thresholds over which non-linearities emerge, is an empirical question.

\subsection{Cross-sectional estimation}

The OLS cross-sectional regression of a crisis indicator on a parsimonious list of covariates, where the dataset is built around a crisis window period, intends to assess if during a period of financial distress the position of a country within the network affects its performance, either by providing ways to diffuse/assimilate shocks, or by making the country prone to contagion (Kali and Reyes, 2010).

Our benchmark econometric specification reads:

$$
y_{i, 2008}=\gamma x_{i, 2006}^{\prime}+\theta g_{i, 2006}+v_{i, 2008}
$$

where $y_{i}$ is any crisis measure, $x_{i t}$ is a vector of macro-economic controls, $g_{i t}$ is a vector of network measures, $u_{i}$ is the error component and $i=\{1 \ldots 74\}$.

Since most of the previous studies has opted for real measures of crisis intensity, we set off by looking at the percentage change in real GDP between the second quarter of 2008 and the second quarter of 2009, in line with Rose and Spiegel (2011). ${ }^{3}$

\footnotetext{
${ }^{3}$ Blanchard et al. (2010) correct real GDP growth by subtracting average growth over the period 1995-2007.
} 
As to the covariates, taking stock of the literature, we select a small number of explanatory variables, all referring to 2006 in order to limit possible endogeneity: income as measured by real per capita GDP (in logs), an inverse measure of credit market regulation (higher figures imply less regulation), bank credit to the private sector over GDP, and current account over GDP. ${ }^{4}$ Results from fitting eq. (1) to the data are reported in Table 1.

Table 1: Cross-sectional regression analysis. Dependent variable: percentage change in real GDP

\begin{tabular}{llllll}
\hline & $(1)$ & $(2)$ & $(3)$ & $(4)$ & $(5)$ \\
& baseline & NDin & NDin & NDout & NDout \\
\hline & & & & & \\
log real pc GDP & -1.817 & $-3.153^{* *}$ & $-3.334^{* *}$ & -1.615 & -0.941 \\
credit mkt regul & $-1.621^{* *}$ & $-1.409^{*}$ & $-1.212^{*}$ & $-1.656^{* *}$ & $-1.568^{* *}$ \\
domcredprvy & $0.024^{* *}$ & 0.017 & $0.021^{* *}$ & $0.025^{* *}$ & $0.022^{* *}$ \\
caccyrat & $0.123^{*}$ & 0.096 & $0.126^{*}$ & $0.134^{*}$ & $0.108^{*}$ \\
NDin & & $0.075^{*}$ & $-0.130^{* *}$ & & \\
log NDin & & & $7.007^{* * *}$ & & \\
NDout & & & & -0.019 & -0.432 \\
$\log$ NDout & & & & & 18.165 \\
\hline Obs. & 53 & 53 & 52 & 53 & 53 \\
Adj.R $R^{2}$ & 0.125 & 0.156 & 0.313 & 0.109 & 0.123 \\
\hline
\end{tabular}

The baseline model without network indicators (column 1) suggests that high income countries and countries with less regulated capital markets suffered more pronounced downturns. Bank credit has a positive, yet rather small, impact on the real economy: while this may appear counterintuitive at first, since the financial crisis should have hit more severely countries where credit had been overabundant, larger amount of bank credit helped to sustain economic activity or, looking at the flip side, GDP suffered more in countries that experienced more pronounced credit crunches. Finally, as reported elsewhere (Frankel and Saravelos, 2011), larger current account surpluses partly shielded economies from the crisis.

In columns $(2-5)$ we add network measures in the form of in- and out-degree. ${ }^{5}$ In-degree (number of countries whose securities are held by the country under consideration) exerts a positive effect on GDP growth; even when we add a logarithmic term to account for possible nonlinear effects, the marginal effect of an increase in in-degree remains positive for most values, turning negative only for very high values of the index (namely for in-degree larger than 60 over a maximum of 73). Furthermore, inclusion of this (linear and log) network indicator This correction does not alter the main results so that we stick to the original measure.

${ }^{4}$ Data are taken from the World Development Indicators (World Bank), apart from credit market regulation, which comes from the Economic Freedom of the Word database maintained by the Fraser's Institute.

${ }^{5}$ Network measures are based on Total Portfolio holdings. We experimented with a number of higher-order measures besides node degree, but the associated coefficients turned out to be seldom significant. 
significantly improves the fit of the regression, raising the adjusted $R^{2}$ from 0.125 to 0.313 . On the contrary, the number of creditors of a country (out-degree) does not have a significant impact on the performance of the real economy during the period under scrutiny.

Although of the previous literature has focused on real measures of crisis intensity, it can be argued that until early 2009 the crisis had remained mainly financial, with its full impact on the real economy not yet apparent. We wonder, then, whether the lack of strong results may simply come from the choice of the crisis measure.

To investigate the issue further we replicate our econometric exercise using as the dependent variable volatility adjusted stock market returns between Sep. 15, 2008 and Mar 31, 2009 (Frankel and Saravelos, 2011) computed as:

$$
r_{\text {adjusted }}=\frac{\left[\left(P_{t=T} / P_{t=0}\right)^{252 / N}-1\right] \times 100}{\operatorname{std}\left(\left(\left(P_{t} / P_{t-1}\right)^{252 / N}-1\right) \times 100\right)},
$$

where $P_{t}$ are stock prices at time $t, N$ is the number of observations and $\operatorname{std}(X)$ is the standard deviation of $X{ }^{6}$

Table 2: Cross-sectional regression analysis. Dependent variable volatility adjusted stock market returns

\begin{tabular}{|c|c|c|c|c|c|c|c|}
\hline & \multirow{2}{*}{$\begin{array}{l}(1) \\
\text { baseline }\end{array}$} & $(2)$ & $(3)$ & $(4)$ & $(5)$ & (6) & $(7)$ \\
\hline & & \multicolumn{2}{|c|}{ NDin } & \multicolumn{2}{|c|}{ NDout } & ANND & outout \\
\hline log real pc GDP & $-2.575^{* * *}$ & $-6.331^{* * *}$ & $-7.375^{* * *}$ & $-5.438^{* * *}$ & $-3.500^{* * *}$ & $-5.622^{* * *}$ & $-4.328^{* * *}$ \\
\hline credit mkt regul & -1.063 & -0.784 & -1.031 & -0.448 & 0.083 & -0.571 & -0.234 \\
\hline Bk NPL/Loans & $-0.397 * * *$ & $-0.452^{* * *}$ & $-0.626^{* * *}$ & $-0.379^{* * *}$ & $-0.288^{* *}$ & $-0.434^{* * *}$ & $-0.390 * * *$ \\
\hline curr. acc. /GDP & $0.136^{*}$ & $0.166^{* *}$ & $0.183^{* * *}$ & $0.134^{* * *}$ & $0.092^{* * *}$ & $0.115^{* *}$ & 0.066 \\
\hline NDin & & $0.141^{*}$ & $0.279^{* *}$ & & & & \\
\hline $\log$ NDin & & & $-4.333^{* *}$ & & & & \\
\hline NDout & & & & $0.198^{* *}$ & $-0.764^{* *}$ & & \\
\hline $\log$ NDout & & & & & $41.578^{* *}$ & & \\
\hline ANND out-out & & & & & & $-0.726^{* *}$ & $-11.841^{*}$ \\
\hline $\log$ ANND out-out & & & & & & & $562.868^{*}$ \\
\hline Obs. & 47 & 47 & 47 & 47 & 47 & 47 & 47 \\
\hline $\operatorname{Adj} . R^{2}$ & 0.140 & 0.265 & 0.316 & 0.388 & 0.519 & 0.363 & 0.403 \\
\hline
\end{tabular}

Column (1) reports the baseline model without network indicators. We see that richer countries experienced a larger downturn in stock market performance, as they were more heavily exposed to the subprime and the U.S. financial market. Credit market regulation seems not to play a relevant role here, whereas the health of the banking sector does influence the overall performance of the market. Finally, a positive current account balance limits the intensity of

\footnotetext{
${ }^{6}$ Data for the relevant stock market indexes are retrieved from Datastream.
} 
the crisis.

When we augment the econometric model by means of network measures, the fit improves substantially, with the adjusted $R^{2}$ moving from 0.14 to 0.27 (column 2), or even to 0.52 (column 5). Both node in- and out-degree have the same behavior when entered linearly in the regression: having more creditors or more debtors increases stock market performance. However, when we add both a linear and logarithmic term in order to gage the presence of nonlinear effects, the behavior changes slightly. The estimated coefficients imply that, all else equal, an increase in the number of debtors (in-degree) for a country has a negative effect for very low values of in-degree, but starts exerting a positive impact for values as low as 15 . When we turn to the number of creditors (out-degree) the marginal effect of higher connectedness is positive for all meaningful values of the statistic.

Previously, we stated that the average nearest neighbor degree $(A N N D)$ allows to move two-step away from each node, and look and the average number of partners of its immediate neighbors. Table 2 reports results for $A N N D_{-}$outout, i.e. the average number of creditors of a country's creditors. As explained before, a higher number indicates a more complex chain of credit flows potentially testifies for higher liquidity thus implying higher resilience to shocks, but also a higher probability that some of the two-step away partner is hit by a shock. Estimation results suggest stock market returns are increasing in $A N N D$ up to values around 47, then slightly decreasing. ${ }^{7}$

Overall, the cross-sectional analysis provides prima facie evidence that adding network measures does improve the explanatory power of the empirical model. Furthermore, we also find evidence of nonlinear effects: in line with the recent theoretical models (Iori et al., 2006; Caccioli et al., 2011; Haldane and May, 2011), the high degree of heterogeneity that characterizes the IFN breaks down the monotone relationship between connectedness and diversification benefits, making the network more robust, yet more fragile.

Thus far we have limited the analysis to Total Portfolio holdings only, and restricted the number of econometric specifications for which we present detailed results. In what follows we provide a far richer analysis based on GMM panel regressions, which enable us to overcome (at least partially) potential problems related to the small sample size, endogeneity and the omitted variable bias. Given that results based on stock market returns perform better than

\footnotetext{
${ }^{7}$ It is worth noting that the mean for ANND_outout is around 42.
} 
those obtained looking at the change in real GDP, that in the previous literature the choice of either one seems not to dramatically affect the outcome of the analysis, and that we will explore a relatively large number of different specifications, in the rest of the econometric exercise we use adjusted returns as our preferred crisis indicator.

\subsection{Panel GMM estimation}

The "ideal" model to estimate in the panel GMM setting is:

$$
\begin{aligned}
& y_{i t}=\alpha x_{i t}+\beta g_{i t}+c_{i}+u_{i t} \\
& g_{i t}=\gamma x_{i t}^{\prime}+\theta y_{i t}+c_{i}+v_{i t}
\end{aligned}
$$

where, again, $y_{i t}$ is any measure of financial crisis, $x_{i t}$ is the vector of economic controls, $g_{i t}$ is the vector of network measures, $c_{i}$ is the individual unobserved effect and $u_{i t}$ is the error component, $i=\{1 \ldots 74\}$ and $t=\{2001 \ldots 2008\}$. However, we are just interested in the estimation of the first equation of the system. Therefore, the problems reside in how to remove $c_{i}$ and how to cope with the fact that $g$ is endogenous.

We use Arellano-Bond difference estimator (Arellano and Bond, 1991) to remove the individual effects that make the error term both autocorrelated and correlated with the lagged dependent variable. To deal with this we can use $y_{i t-k}$ with $k>1$ as instruments for $\Delta y_{i t-1}$. That is, we can use the moment condition: $\mathbb{E}\left(\Delta u_{i t} y_{i t-k}\right)=0, k>1$. As a consequence, we assume only sequential exogeneity, not strict exogeneity of the error term. The asymptotic covariance matrix is computed in the standard 2-step way with the addition of the Windmeijer (2005) correction for finite-samples. Given that we want to control for the crisis period (2008) in the panel estimation, we include crisis dummies variables as interaction terms with the network indicators.

Although the proposed GMM approach is a first step in the right direction, it seems that we have to further refine the estimation exercise in order to address the robustness and reliability of our results. There are a number of issues that one can think when reporting the results for regressions based on a given set of economic and network controls. It is plausible to think that multiple network measures could be included in the regression and different indicators are 
statistically significant for the different layers of the IFN (total portfolio investments, equities, total debt securities, short- and long-term debt).

However, the small sample size does not allow for specifications where many network indicators are included simultaneously as controls: this could lead to statistical anomalies and small sample biases. The problem of the number of observations is not something that can be fixed, but it is possible to perform a more thorough exploratory exercise where the different layers of the IFN are considered and also more network indicators are included.

Using the GMM estimation described above and the same economic controls as in all the previous regressions, we look at different econometric specifications that include four network variables at a time, out of all the following network variables, specified both in levels and in logs: NDin, NDout, ANND_inin, ANND_inout, ANND_outin, ANND_outout, NSin, NSout, ANNS_inin, ANNS_inout, ANNS_outin, ANNS_outout, BCC, WCC, binary authority centrality (BAC), binary hub centrality (BHC), weighted authority centrality (WAC) and weighted hub centrality (WHC).

The four network controls selected enter the regression with their respective crisis dummy interaction term. We estimate regressions that result from all possible combinations for the network indicators. There are 26 network indicators to be considered but these can be used in levels or logs (for a total of 52). Therefore, there are 270725 possible econometric specifications to be estimated for each of the IFN layers, for a grand total of 1353625 regressions.

The reason for estimating all possible combinations relies on the desire of checking for the robustness of the results. One could select one specification and interpret the coefficients and their statistical significance but here we want to see how stable are the results for the network effects when considering all possible specifications.

In order to visualize and interpret the results we use filled contour plots that show the bi-variate density of the estimated coefficients with their respective p-values. Each contour plot contains - on average - 9000 coefficient/p-values pairs. The idea is that if the density is concentrated around a given range, far from zero, for the coefficient and at low p-values (below 0.1) this can be used to argue that the regressor is likely to be positively or negatively significant. We show two examples of significant regressors in Figure 10 and two examples of not significant regressors in Figure 11 (all the others plots are available upon request). In Table 
3, instead, we report mean, median and standard deviations of the significant variables.

Table 3: GMM regression analysis: significant regressors

\begin{tabular}{|c|c|c|c|c|}
\hline Regressor & Layer & Mean & Median & STD \\
\hline caccyrat & & 3.16 & 3.12 & 0.63 \\
\hline $\ln \_g d p \_p p p$ & & -163.89 & -160.10 & 54.83 \\
\hline \multirow[t]{3}{*}{ NDin } & TPI & 4.42 & 4.32 & 1.22 \\
\hline & ES & 3.22 & 3.22 & 0.66 \\
\hline & TDS & 3.94 & 3.77 & 1.01 \\
\hline \multirow[t]{2}{*}{ NDout } & TPI & 2.64 & 2.63 & 0.82 \\
\hline & $\mathrm{ES}$ & 2.01 & 1.97 & 0.48 \\
\hline \multirow[t]{2}{*}{$\log ($ NDout $)$} & TPI & 70.50 & 53.68 & 51.90 \\
\hline & TDS & 58.15 & 43.20 & 46.81 \\
\hline \multirow[t]{2}{*}{ ANND_inin } & TPI & 7.09 & 7.37 & 5.96 \\
\hline & TDS & 5.92 & 6.19 & 5.45 \\
\hline \multirow[t]{2}{*}{$\log \left(\mathrm{ANND} \_\right.$inin $)$} & TPI & 430.35 & 371.23 & 201.90 \\
\hline & TDS & 345.64 & 295.90 & 165.83 \\
\hline \multirow[t]{2}{*}{ ANND_inout } & TPI & 3.27 & 5.10 & 6.26 \\
\hline & TDS & 5.24 & 5.26 & 3.73 \\
\hline \multirow[t]{2}{*}{$\log (\mathrm{ANND}$ _inout $)$} & TPI & 331.32 & 302.90 & 214.95 \\
\hline & TDS & 323.83 & 287.10 & 138.26 \\
\hline \multirow[t]{2}{*}{ ANND_outout } & TPI & 4.01 & 4.29 & 3.69 \\
\hline & TDS & 3.018 & 3.03 & 3.43 \\
\hline \multirow[t]{2}{*}{$\log (\mathrm{ANND}$ _outout $)$} & TPI & 249.60 & 209.29 & 144.25 \\
\hline & TDS & 195.05 & 148.03 & 126.88 \\
\hline $\mathrm{BCC}$ & TPI & -294.05 & -322.57 & 326.26 \\
\hline \multirow[t]{3}{*}{$\log (\mathrm{BCC})$} & TPI & -212.08 & -242.47 & 244.30 \\
\hline & $\mathrm{ES}$ & -232.19 & -226.39 & 64.84 \\
\hline & TDS & -211.80 & -207.77 & 125.65 \\
\hline $\mathrm{BAC}$ & TDS & -10460.26 & -9954.8 & 2703.47 \\
\hline \multirow[t]{2}{*}{$\log (\mathrm{BAC})$} & TPI & -143.59 & -126.37 & 66.99 \\
\hline & TDS & -122.75 & -103.84 & 70.40 \\
\hline \multirow[t]{2}{*}{$\log (\mathrm{NSin})$} & TPI & 44.13 & 42.03 & 17.36 \\
\hline & $\mathrm{ES}$ & 30.05 & 28.34 & 8.22 \\
\hline \multirow[t]{2}{*}{$\log$ (NSout) } & TPI & 27.34 & 25.90 & 8.01 \\
\hline & $\mathrm{ES}$ & 16.17 & 14.88 & 6.46 \\
\hline \multirow[t]{2}{*}{$\log \left(\mathrm{ANNS} \_\right.$inin $)$} & TPI & 96.19 & 95.11 & 22.94 \\
\hline & TDS & 89.40 & 88.45 & 21.47 \\
\hline \multirow[t]{2}{*}{$\log (\mathrm{ANNS}$ _inout $)$} & TPI & 97.65 & 96.49 & 22.43 \\
\hline & TDS & 88.70 & 87.04 & 22.10 \\
\hline \multirow[t]{3}{*}{$\log ($ ANNS_outout $)$} & TPI & 20.74 & 15.63 & 28.52 \\
\hline & $\mathrm{ES}$ & 23.17 & 15.23 & 17.48 \\
\hline & TDS & 35.81 & 25.74 & 28.52 \\
\hline \multirow[t]{3}{*}{$\log (\mathrm{WCC})$} & TPI & 71.14 & 71.28 & 21.47 \\
\hline & $\mathrm{ES}$ & 75.90 & 77.0375 & 9.88 \\
\hline & TDS & 57.73 & 56.09 & 19.45 \\
\hline
\end{tabular}

The results show that many of the significant regressors have positive effects on the stock market returns and these findings provide support for the risk diversification hypothesis. However, we cannot completely rule out the notion that higher connectedness also increase vulnerability. On the one hand, when we look at first and second order measures (node degree/strength indicators and average nearest neighbor degree/strength indicators), it appears that being well connected and having well connected neighbors is beneficial for the performance of a country. 
On the other hand, when we look at higher order statistics (like clustering and centrality), the picture is somewhat different. Indeed, high authority scores and clustering in the binary networks increases the risk of being negatively hit in a considerable way, probably because when a shock hits one of the members of the cluster, then all the others are immediately affected as well. At the same time, a high WCC shields countries from financial contagion, a result that is driven by the fact that higher values for this index are associated with lower heterogeneity in the strength of links within the cluster. These results confirm that knowing the exact role and position of a country within the IFN does matter when we are dealing with the transmission of shocks.

The results of the current study also shed some light on the discussion regarding whether or not the degree of connectivity for a country leads to different dynamics during the recent financial crisis when compared to previous (stable) years. Based on the contour plots we studied, the coefficients of the interaction effects between the crisis dummies and the network indicators are not significant. In other words, it is not possible to reject the hypothesis that the effect of network connectivity on economic (stock market) performance is the same in both pre-crisis and crisis years. This is a relevant finding because it suggests not only that network indicators can be used to predict country vulnerability to shocks, but also that their role is stable during periods of substantial market distress, making them all the more useful and important from a policy perspective.

\section{Conclusions}

We have analyzed the structural properties of the IFN in the period 2001-10, and found that the network is characterized by a disassortative core-periphery architecture and the presence of a small number of financial hubs forming a rich-club. The 2007-2008 crisis resulted not only in a reduction in the amount of securities traded, but also induced changes in the topology of the network and in the time evolution of its statistical properties. This has happened, however, without changing the disassortative, core-periphery structure of the IFN architecture.

These descriptive results have been used to feed econometric models where measures of crisis intensity are regressed against macroeconomic variables and network measures. Using both cross-sectional and panel GMM techniques we find that network measures provide useful 
information and improve the fit of empirical models used in the literature on early warning systems.

Consistently with theoretical models of network dynamics and evolution (such as Allen and Gale, 2000; Gai and Kapadia, 2010) we have found here that higher interconnectedness reduces the severity of the crisis, as it allows adverse shocks to dissipate quicker. However, the systemic risk hypothesis cannot be completely dismissed and being central in the network, if the node is not a member of a rich club, puts the country in an adverse and risky position in times of crises. Moreover, we find strong evidence of nonlinear effects, as predicted by recent theoretical models (Iori et al., 2006; Caccioli et al., 2011) once the high degree of heterogeneity that characterizes the IFN is taken into account.

Our analysis can be extended in at least three ways. First, one interesting route for future research might involve performing network-resilience tests to evaluate the impact of nodetargeted shocks or node failures on network structure, given the high degree of heterogeneity featured by the IFN. Second, one may explore in more detail the space of crisis indicators, possibly building synthetic measures in line with Rose and Spiegel (2010). Finally, the impact of country network-position on early-warning systems might be studied in more detail, focusing not only on country network profiles within the IFN, but also within a more general macroeconomic multi-network where countries are nodes and links represent a host of macroeconomic interlinkages and interaction channels, including financial relations, trade in goods and services, foreign direct investment, migrations and the like.

\section{References}

Allen, F. and Babus, A., 2009. Networks in Finance. In The Network Challenge, P. Kleindorfer and J. Wind (eds). Wharton School Publishing. pp. 367-382.

Allen, F. and Gale, D., 2000. Financial contagion. Journal of Political Economy. 1081, 1-33.

Arellano, M. and Bond, S., 1991. Some Tests of Specification for Panel Data: Monte Carlo Evidence and an Application to Employment Equations. The Review of Economic Studies. $582,277-297$.

Battiston, S., Delli Gatti, D., Gallegati, M., Greenwald, B. and Stiglitz, J. E., 2011. Default 
Cascades: When Does Risk DiversiïnAzcation Increase Stability?. Working Paper Series ETHRC-11-006. ETH Risk Center.

Berkmen, P., Rennhack, R., Walsh, J. P. and Gelos, G., 2009. The Global Financial Crisis: Explaining Cross-Country Differences in the Output Impact. IMF Working Papers 09/280. International Monetary Fund.

Blanchard, O. J., Das, M. and Faruqee, H., 2010. The Initial Impact of the Crisis on Emerging Market Countries. Brookings Papers on Economic Activity. 411 (Spring), 263-323.

Caccioli, F., Catanach, T. A. and Farmer, J. D., 2011. Heterogeneity, Correlations and Financial Contagion. Working Paper 11-09-44. Santa Fe Institute.

Calvo, G. A., 1998. Capital Flows and Capital-Market Crises: The Simple Economics of Sudden Stops. Journal of Applied Economics. I, 35-54.

Claessens, S., Dell'Ariccia, G., Igan, D. and Laeven, L., 2010. Cross-country experiences and policy implications from the global financial crisis. Economic Policy. 25, 267-293.

Cocco, J., Gomes, F. and Martins, N., 2009. Lending relationships in the interbank market. Journal of Financial Intermediation. 181, 24-48.

Fagiolo, G., 2006. Directed or Undirected? A New Index to Check for Directionality of Relations in Socio-Economic Networks. Economics Bulletin. 3, 1-12.

Fagiolo, G., Schiavo, S. and Reyes, J., 2009. World-trade web: Topological properties, dynamics, and evolution. Physical Review E. 79, 036115.

Frankel, J. and Saravelos, G., 2011. Can Leading Indicators Assess Country Vulnerability? Evidence from the 2008-09 Global Financial Crisis. Working Paper Series rwp11-024. Harvard University, John F. Kennedy School of Government.

Freixas, X., Parigi, B. and Rochet, J., 2000. Systemic risk, interbank relations, and liquidity provision by the central bank. Journal of money, credit and banking. pp. 611-638.

Gai, P. and Kapadia, S., 2010. Contagion in financial networks. Proceedings of the Royal Society A: Mathematical, Physical and Engineering Science. 4662120, 2401. 
Giannone, D., Lenza, M. and Reichlin, L., 2011. Market Freedom and the Global Recession. IMF Economic Review. 591, 111-135.

Haldane, A. and May, R., 2011. Systemic risk in banking ecosystems. Nature. 4697330, 351-355.

Hale, G., 2011. Bank Relationships, Business Cycles, and Financial Crises. Working Paper 17356. National Bureau of Economic Research.

Iori, G., Jafarey, S. and Padilla, F. G., 2006. Systemic risk on the interbank market. Journal of Economic Behavior \& Organization. 614, $525-542$.

Kali, R. and Reyes, J., 2010. Financial contagion on the international trade network. Economic Inquiry. 484, 1072-1101.

Kleinberg, J., 1999. Authoritative sources in a hyperlinked environment. Journal of the ACM (JACM). 465, 604-632.

Lane, P. R. and Milesi-Ferretti, G. M., 2011. The Cross-Country Incidence of the Global Crisis. IMF Economic Review. 591, 77-110.

Leitner, Y., 2005. Financial networks: Contagion, commitment, and private sector bailouts. Journal of Finance. 606, 2925-2953.

Minoiu, C. and Reyes, J. A., 2011. A network analysis of global banking: 1978-2009. Working Paper 11/74. IMF.

Opsahl, T., Colizza, V., Panzarasa, P. and Ramasco, J., 2008. Prominence and control: The weighted rich-club effect. Physical Review Letters. 10116, 168702.

Rose, A. K. and Spiegel, M. M., 2010. Cross-Country Causes And Consequences Of The 2008 Crisis: International Linkages And American Exposure. Pacific Economic Review. 153, 340363.

Rose, A. K. and Spiegel, M. M., 2011. Cross-country causes and consequences of the crisis: An update. European Economic Review. 553, 309-324.

Schiavo, S., Reyes, J. and Fagiolo, G., 2010. International trade and financial integration: a weighted network analysis. Quantitative Finance. 104, 389-399. 
Schweitzer, F., Fagiolo, G., Sornette, D., Vega-Redondo, F., Vespignani, A. and White, D., 2009. Economic Networks: The New Challenges. Science. 325, 422-425.

von Peter, G., 2007. International banking centres: a network perspective. BIS Quarterly Review. November, 33-45.

Windmeijer, F., 2005. A finite sample correction for the variance of linear efficient two-step GMM estimators. Journal of Econometrics. 1261, 25-51.

\section{A Aggregate Network Statistics}

In this Appendix we provide formal definitions for aggregate (network-wide) statistics. We begin by:

Network Density (dens) Let $m$ bet the number of edges present in the network in a given year and $\mathrm{N}$ be the number of nodes (i.e. countries). Then, we define the network density (dens) as $\frac{m}{N(N-1)}$.

Asymmetry of a binary or weighted-directed network can be measured in many ways. First, one can assess the extent to which a network is asymmetric by computing the index proposed in Fagiolo (2006). This is obtained as an average over all the links of squared differences between $i j$ and $j i$ adjacency- or weight-matrix entries, properly rescaled by the norm of the weight or adjacency matrix itself. The index has nice properties and can be shown to be normallydistributed under some mild conditions about link-weight distribution. In a weighted network, however, this index treats all link unbalances the same, as it does not consider the relative impact that a given unbalance might have over total weight carried by a directed link, i.e. the sum of $i j$ and $j i$ weights. Since in principle it may be interesting to compute also asymmetry over relative-unbalance averages, we define the following:

Relative Binary Network Asymmetry (basym) Let $A$ bet the binary adjacency matrix of the network in a given year and $\mathrm{N}$ be the number of nodes (i.e. countries). Then, we define the network binary asymmetry (basym) as $\frac{1}{N(N-1)} \sum_{i, j \in \mathbf{N}}\left|\frac{A(i, j)-A(j, i)}{A(i, j)+A(j, i)+\delta(A(i, j)+A(j, i))}\right|$, where $\delta(x)$ is the Dirac delta function. 
Relative Weighted Network Asymmetry (wasym) Let $W$ bet the weighted adjacency matrix of the network in a given year and $\mathrm{N}$ be the number of nodes (i.e. countries). Then, we define the network weighted asymmetry (wasym) as $\frac{1}{N(N-1)} \sum_{i, j \in \mathbf{N}}\left|\frac{W(i, j)-W(j, i)}{W(i, j)+W(j, i)+\delta(W(i, j)+W(j, i))}\right|$, where $\delta(x)$ is the Dirac delta function.

Density and asymmetry measures are bounded between zero and one. Density is equal to one when the graph is complete and to zero when there are no links between the nodes. Relative-unbalance asymmetry indicators equal one (indicating perfect asymmetry) when $i j$ and $j i$ links exist only in one direction; and zero (perfect symmetry) when $i j$ and $j i$ links exist in both directions (and have the same weights). We refer to Fagiolo (2006) for the statistical properties of the level-unbalance asymmetry indicator.

\section{B Node-Specific Binary Node Network Statistics}

The most important node-specific binary network statistics employed in the paper are:

Node in-degree ( $N$ Din $)$ Let $e_{i j}=1$ if there exists an edge from country $i$ to country $j$ and let $N_{i}^{i n}$ be the set of in-neighbors of country $i$. Then, we define country $i$ 's node in-degree as: $N \operatorname{Din}_{i}=\sum_{j \in N_{i}^{i n}} e_{j i}$. From an economic point of view, node in-degree in the IFN is the number of debtors that country $i$ has.

Node out-degree (NDout) Let $e_{i j}=1$ if there exists an edge from country $i$ to country $j$ and let $N_{i}^{\text {out }}$ be the set of out-neighbors of country $i$. Then, we define country $i$ 's node outdegree as: $N$ Dout $_{i}=\sum_{j \in N_{i}^{\text {out }}} e_{i j}$. From an economic point of view, node out-degree in the IFN is the number of creditors that country $i$ has.

Total Node degree $(N D)$ We define total node degree as the sum of node in-degree and node out-degree, i.e. $N D_{i}=N \operatorname{Din}_{i}+N$ Dout $_{i}$. From an economic point of view, total node degree in the IFN is the number of creditors and debtors that country $i$ has.

Average nearest-neighbor degree $(\boldsymbol{A N N D})$ Let $N_{i}$ be the set of neighbors of country $i$, then we define average nearest-neighbor degree as: $A N N D=\frac{\sum_{j \in N_{i}} N D_{j}}{N D_{i}}$. From an economic point of view, average nearest-neighbor degree in the IFN tells us how many creditors/debtors have - on average - country $i$ 's creditors/debtors. 


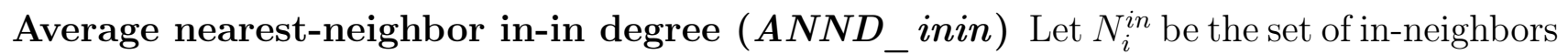
of country $i$, then we define average in-in nearest-neighbor degree as: $A N N D_{-} i n i n=\frac{\sum_{j \in N_{i}^{i n} N \operatorname{Din}_{j}}}{N \operatorname{Din}_{i}}$. From an economic point of view, average nearest-neighbor in-in degree in the IFN tells us how many debtors have - on average - country $i$ 's debtors.

Average nearest-neighbor in-out degree $\left(A N N D_{-}\right.$inout $)$Let $N_{i}^{\text {in }}$ be the set of in-neighbors of country $i$, then we define average nearest-neighbor in-out degree as: $A N N D$ _inout $=$ $\frac{\sum_{j \in N_{i}^{i n} N \text { Dout }_{j}}}{N \text { Din }_{i}}$. From an economic point of view, average nearest-neighbor in-out degree in the IFN tells us how many creditors have - on average - country $i$ 's debtors.

Average nearest-neighbor out-in degree ( $A N N D_{-}$outin $)$Let $N_{i}^{\text {out }}$ be the set of outneighbors of country $i$, then we define average nearest-neighbor out-in degree as: ANND_outin= $\frac{\sum_{j \in N_{i}^{\text {out }}} N \operatorname{Din}_{j}}{N \text { Dout }_{i}}$. From an economic point of view, average nearest-neighbor out-in degree in the IFN tells us how many debtors have - on average - country $i$ 's creditors.

Average nearest-neighbor out-out degree ( $A N N D_{-}$outout $)$Let $N_{i}^{\text {out }}$ be the set of outneighbors of country $i$, then we define average nearest-neighbor out-out degree as: $A N N D$ _outout $=$ $\frac{\sum_{j \in N_{i}^{\text {out }}} \text { NDout }_{j}}{N \text { Dout }_{i}}$. From an economic point of view, average nearest-neighbor out-out degree tells us how many creditors have - on average - country $i$ 's creditors.

Binary clustering coefficient $(B C C)$ Binary clustering coefficient expresses the likelihood that any two neighbors of a country are also neighbors of themselves. Then, we define the binary clustering coefficient for country $i$ as: $B C C_{i}=\frac{\left(A^{3}\right)_{i i}}{N D_{i}\left(N D_{i}-1\right)}$. From an economic point of view, binary clustering tells us which is the probability that two creditors/debtors of a country are also creditors/debtors among themselves.

\section{Weighted Node Network Statistics}

The most important node-specific weighted network statistics employed in the paper are:

Node in-strength (NSin) Let $w_{i j}$ be the weight associated to the edge leaving country $i$ and reaching country $j$ and let $N_{i}^{i n}$ be the set of in-neighbors of country $i$. Then, we define country $i$ 's node in-strength as: $N \operatorname{Sin}_{i}=\sum_{j \in N_{i}^{i n}} w_{j i}$. From an economic point of view, node 
in-strength is the total amount of credit that country $i$ has accumulated with respect to its neighbors or, putting it differently, the amount of investments that country $i$ has made on its neighbors.

Node out-strength (NSout) Let $w_{i j}$ be the weight associated to the edge leaving country $i$ and reaching country $j$ and let $N_{i}^{\text {out }}$ be the set of out-neighbors of country $i$. Then, we define country $i$ 's node out-strength as: $N$ Sout $_{i}=\sum_{j \in N_{i}^{\text {out }}} w_{i j}$. From an economic point of view, node out-strength is the total amount of debt that country $i$ has accumulated with respect to its neighbors or, putting it differently, the amount of investments $i$ 's neighbors have made in the country.

Total node strength $(\boldsymbol{N} S)$ We define total node strength as the sum of node in-strength and node out-strength, i.e. $N S_{i}=N \operatorname{Sin}_{i}+N S_{\text {out }}$. From an economic point of view, total node strength is the overall amount of dollars of securities issued or held by country $i$.

Average nearest-neighbor strength $(\boldsymbol{A N N S})$ Let $N_{i}$ be the set of neighbors of country $i$, then we define average nearest-neighbor strength as: $A N N S=\frac{\sum_{j \in N_{i}} N S_{j}}{N D_{i}}$. From an economic point of view, average nearest-neighbor strength tells us - on average - the overall amount of dollars of securities issued or held by country $i$ 's creditors/debtors.

Average nearest-neighbor in-in strength $(\boldsymbol{A N N S}$ inin $)$ Let $N_{i}^{i n}$ be the set of in-neighbors of country $i$, then we define average nearest-neighbor strength in-in as: ANNS_inin = $\frac{\sum_{j \in N_{i}^{i n} N \operatorname{Sin}_{j}}}{N \operatorname{Din}_{i}}$. From an economic point of view, average nearest-neighbor in-in strength tells - on average - the overall amount of dollars of securities held by country $i$ 's debtors.

Average nearest-neighbor in-out strength $\left(A N N S_{-}\right.$inout $)$Let $N_{i}^{\text {in }}$ be the set of inneighbors of country $i$, then we define average nearest-neighbor in-out strength as: ANNS_inout= $\frac{\sum_{j \in N_{i}^{i n}} N \text { Sout }_{j}}{N \text { Din }_{i}}$. From an economic point of view, average in-out nearest-neighbor strength tells us - on average - the overall amount of dollars of securities issued by country $i$ 's debtors.

Average nearest-neighbor out-in strength (ANNS_outin) Let $N_{i}^{\text {out }}$ be the set of outneighbors of country $i$, then we define average nearest-neighbor out-in strength as: ANND_outin= $\frac{\sum_{j \in N_{i}{ }^{\text {out }}} N \operatorname{Sin}_{j}}{N \text { Dout }_{i}}$. From an economic point of view, average nearest-neighbor out-in strength tells us - on average - the overall amount of dollars of securities held by country $i$ 's creditors. 
Average nearest-neighbor out-out strength ( $A N N S_{-}$outout $)$Let $N_{i}^{\text {out }}$ be the set of out-neighbors of country $i$, then we define average nearest-neighbor out-out strength as: ANNS_outout $=$ $\frac{\sum_{j \in N_{i}^{\text {out }}} N_{\text {Sout }_{j}}}{\text { DDout }_{i}}$. From an economic point of view, average nearest-neighbor out-out strength tells us - on average - the overall amount of dollars of securities issued by country $i$ 's creditors.

Weighted clustering coefficient ( $\boldsymbol{W C} \boldsymbol{C}$ ) Weighted clustering coefficient expresses the weighted likelihood that any two neighbors of a country are also neighbors of themselves considering the intensity of their interactions. That is, we define the weighted clustering coefficient for country $i$ as: $W C C_{i}=\frac{\left(W^{\frac{1}{3}}\right)_{i i}^{3}}{N D_{i}\left(N D_{i}-1\right)}$. From an economic point of view, weighted clustering tells us which is the weighted probability that two creditors/debtors of a country are also creditors/debtors among themselves by putting more weight on stronger interactions.

\section{Null Models}

To compute the rich-club coefficient, we have employed the following random null-network models:

- M1 Links are completely reshuffled, i.e. entries of the weighted adjacency matrix are fully permuted;

- M2 Weights are reshuffled but the binary adjacency matrix is kept constant, i.e. only link-weights are shuffled and the degree sequence remains the same;

- M3 Out-links are completely reshuffled, i.e. node out-degree and node out-strength remain constant but the binary adjacency matrix does not;

- M4 Weights of out-links are reshuffled, i.e. node out-degree, node out-strength and the binary adjacency matrix remain constant;

- M5 In-links are completely reshuffled, i.e. node in-degree and node in-strength remain constant but the binary adjacency matrix does not;

- M6 Weights of in-links are reshuffled, i.e. node in-degree, node in-strength and the binary adjacency matrix remain constant. 


\section{E Rich Club Coefficient}

Rich Club Coefficient $(\boldsymbol{R C C})$ Define $r$ as the measure of richness of a node, let $W_{>\bar{r}}$ be the sum of weights of all the links connecting those countries that exhibit a richness parameter larger than a given threshold $\bar{r}$ where the number of such links is $E_{>\bar{r}}$. Define $W_{\text {top }}$ as the sum of the weights associated to the $E_{>\bar{r}}$ strongest links present in the network. Then, if we compute the ratio $\phi^{w}(\bar{r})=\frac{W_{>\bar{r}}}{W_{t o p}}$ both for our original network and for the chosen null model and given $\rho^{w}(\bar{r})=\frac{\phi^{w}(\bar{r})_{\text {original }}}{\phi_{n u l l}^{w}(r)_{\text {null }}}$, we can define the rich-club coefficient as $R C C=\frac{1}{B} \sum_{b=1 . . B} \rho_{b}^{w}(\bar{r})$, where B is the number of network instances generated with the null model.

\section{F Financial Hubs and Authorities}

Tables 4-7 show the rankings of the top 30 countries in each of the four centrality measures considered: binary hub centrality $(B H C)$, binary authority centrality $(B A C)$, weighted hub centrality $(W H C)$ and weighted authority centrality $(W A C)$. 
Table 4: Binary Hub Centrality

\begin{tabular}{|c|c|c|c|c|c|c|c|c|c|c|}
\hline Rank & 2001 & 2002 & 2003 & 2004 & 2005 & 2006 & 2007 & 2008 & 2009 & 2010 \\
\hline 1 & United States & United States & United States & United States & United States & United States & United States & United Kingdom & United States & United States \\
\hline 2 & United Kingdom & United Kingdom & United Kingdom & United Kingdom & United Kingdom & Germany & Luxembourg & United States & Netherlands & Netherlands \\
\hline 3 & $\begin{array}{l}\text { France } \\
\text { Prman }\end{array}$ & Germany & Germany & Germany & Germany & France & Netherlands & Germany & France & Germany \\
\hline 4 & Germany & Netherlands & Netherlands & Netherlands & France & Netherlands & France & France & Luxembourg & Luxembourg \\
\hline 5 & Netherlands & France & $\begin{array}{l}\text { Italy } \\
\text { France }\end{array}$ & France & Netherlands & Italy & Canada & Luxembourg & United Kingdom & Switzerland \\
\hline 6 & Japan & $\begin{array}{l}\text { Canada } \\
\text { Membour }\end{array}$ & $\begin{array}{l}\text { France } \\
\text { ancmbour }\end{array}$ & $\begin{array}{l}\text { Australia } \\
\text { Switzerland }\end{array}$ & Ireland & Luxembourg & United Kingdom & Ireland & & France \\
\hline 7 & $\begin{array}{l}\text { Canada } \\
\text { Italy }\end{array}$ & $\begin{array}{l}\text { Luxembourg } \\
\text { Sweden }\end{array}$ & $\begin{array}{l}\text { Luxembourg } \\
\text { Japan }\end{array}$ & $\begin{array}{l}\text { Switzerland } \\
\text { Italy }\end{array}$ & $\begin{array}{l}\text { Luxembourg } \\
\text { Canada }\end{array}$ & United Kingdom & Ire & Nethe & & $\mathrm{Ca}$ \\
\hline & $\begin{array}{c}\text { Italy } \\
\text { Luxembour }\end{array}$ & $\begin{array}{l}\text { Sweden } \\
\text { Swaly }\end{array}$ & Japan & Italy & Canada & Canada & Germany & Can & $\begin{array}{l}\text { Canada } \\
\text { Cuita }\end{array}$ & United Kingdom \\
\hline $\begin{array}{c}9 \\
10\end{array}$ & $\begin{array}{l}\text { Luxembourg } \\
\text { Switzerland }\end{array}$ & $\begin{array}{c}\text { Italy } \\
\text { Switzerland }\end{array}$ & Canada & Ireland & Switzerland & Cayman Islands & Australia & Switze & Switzerland & \\
\hline 11 & Cayman Is & $\begin{array}{l}\text { Switzerand } \\
\text { Spain }\end{array}$ & $\begin{array}{l}\text { Australia } \\
\text { Switzerland }\end{array}$ & $\begin{array}{l}\text { Luxembourg } \\
\text { Caayman Islands }\end{array}$ & Iust & $\begin{array}{l}\text { Switzer } \\
\text { Irelan }\end{array}$ & 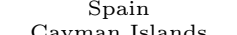 & Caym & Cavma & \\
\hline 12 & $\begin{array}{l}\text { Spain } \\
\text { Spans }\end{array}$ & Belg & Irel & Cane & $\mathrm{Sp}$ & & $\begin{array}{l}\text { Cayman } \\
\text { Ita }\end{array}$ & $\begin{array}{c}\mathrm{Au} \\
\mathrm{It}\end{array}$ & $\begin{array}{l}\text { Cayma } \\
\text { Aus }\end{array}$ & $\begin{array}{l}\text { Cayman } \\
\text { Bra }\end{array}$ \\
\hline 13 & Belgium & Austr & Aust & Sweden & Sweden & Swe & Sweden & Aus & $\mathrm{Sr}$ & \\
\hline 14 & Australia & Japa & Cayman & Jap & ayman Islands & Jap & Switz & & & \\
\hline 15 & $\begin{array}{l}\text { Sweden } \\
\text { Swen }\end{array}$ & yman Islands & Swed & $\mathrm{Sp}$ & Japan & Fin & Jal & & & \\
\hline 16 & Ireland & $\begin{array}{l}\text { Austria } \\
\text { A }\end{array}$ & & Belg & & & & & & Bel \\
\hline 17 & Denmark & & & & & & Nor & & & ussian $\mathrm{F}$ \\
\hline 18 & Aus & & & & & & Russian Federation & Russian & & Swe \\
\hline 19 & & & & Berm & Bermuda & & Belg & & Hong Kong & It: \\
\hline 20 & Ber & & & & Repul & & & & & \\
\hline 21 & Finland & & & Den & Den & Russian $\mathrm{F}$ & & & $\mathrm{f} \mathrm{Ko}$ & \\
\hline 22 & $\mathrm{Br}$ & & & Hong & & & & $\mathrm{De}$ & deration & \\
\hline 23 & ng & & & & Russian & & & Hong & Japan & and \\
\hline 24 & of Korea & Repub & & ion & & & & & & ong \\
\hline 25 & & $\mathrm{H}$ & & & & & & íca & & Korea \\
\hline 26 & A & Russia & issia & Erea & & & & & & \\
\hline 27 & Russian Federation & Thailand & & & & Republ & & & India & \\
\hline 28 & Singapore & Singapore & s thece & Singapore & & Greece & & & South & Hite \\
\hline $\begin{array}{l}29 \\
30\end{array}$ & $\begin{array}{l}\text { Venezuela } \\
\text { Turkey }\end{array}$ & $\begin{array}{l}\text { Turkey } \\
\text { New Zealand }\end{array}$ & $\begin{array}{l}\text { Republic of Korea } \\
\text { Poland }\end{array}$ & $\begin{array}{l}\text { Greece } \\
\text { Argentina }\end{array}$ & $\begin{array}{l}\text { Portugal } \\
\text { New Zealand }\end{array}$ & $\begin{array}{l}\text { Malaysia } \\
\text { South Africa }\end{array}$ & $\begin{array}{l}\text { Netherlands Antilles } \\
\text { Republic of Korea }\end{array}$ & $\begin{array}{l}\text { Mexico } \\
\text { Republic of Korea }\end{array}$ & $\begin{array}{c}\text { Mexico } \\
\text { Netherlands Antilles }\end{array}$ & $\begin{array}{l}\text { South Africa } \\
\text { Poland }\end{array}$ \\
\hline
\end{tabular}


Table 5: Binary Authority Centrality

\begin{tabular}{|c|c|c|c|c|c|c|c|c|c|c|}
\hline Rank & 2001 & 2002 & 2003 & 2004 & 2005 & 2006 & 2007 & 2008 & 2009 & 2010 \\
\hline 1 & Guernsey & Switzerland & Luxembourg & Luxembourg & Luxembourg & United Kingdom & Ireland & Austria & United Kingdom & Guernsey \\
\hline 2 & Luxembourg & Luxembourg & Switzerland & Germany & Ireland & Luxembourg & United Kingdom & Luxembourg & Luxembourg & United Kingdom \\
\hline 3 & United States & United States & United States & $\begin{array}{l}\text { Switzerland } \\
\text { Snited Stato }\end{array}$ & Switzerland & Austria & Austria & Netherlands & Ireland & Luxembourg \\
\hline 4 & Switzerland & Ireland & Germany & United States & Germany & Ireland & Switzerland & Switzerland & Germany & Switzerland \\
\hline 5 & Austria & Austria & Denmark & Ireland & Guernsey & Switzerland & France & France & Austria & Germany \\
\hline 6 & United Kingdom & Italy & Italy & Austria & France & Guernsey & Netherlands & United Kingdom & Switzerland & Austria \\
\hline 7 & Italy & France & Netherlands & Italy & Italy & Germany & Italy & Germany & Netherlands & Ireland \\
\hline 8 & Denmark & Denmark & Ireland & Guernsey & Austria & Netherlands & Germany & Denmark & France & Japan \\
\hline 9 & France & Netherlands & France & United Kingdom & United States & France & Denmark & Italy & Denmark & Italy \\
\hline 10 & Germany & Guernsey & Austria & France & Netherlands & Italy & Luxembourg & Ireland & United States & France \\
\hline 11 & Netherlands & Germany & Guernsey & Netherlands & Denmark & Denmark & United States & Guernsey & Belgium & United \\
\hline $\begin{array}{l}12 \\
13\end{array}$ & $\begin{array}{l}\text { Belgium } \\
\text { Japan }\end{array}$ & $\begin{array}{l}\text { Belgium } \\
\text { Japan }\end{array}$ & $\begin{array}{l}\text { Belgium } \\
\text { Jersey }\end{array}$ & $\begin{array}{l}\text { Jersey } \\
\text { Denmark }\end{array}$ & $\begin{array}{l}\text { Jersey } \\
\text { Canada }\end{array}$ & $\begin{array}{l}\text { Japan } \\
\text { United States }\end{array}$ & $\begin{array}{l}\text { Japan } \\
\text { Belgium }\end{array}$ & $\begin{array}{l}\text { United States } \\
\text { Norway }\end{array}$ & $\begin{array}{l}\text { Japan } \\
\text { Italy }\end{array}$ & $\begin{array}{l}\text { Netherlands } \\
\text { Denmark }\end{array}$ \\
\hline 14 & Bermuda & Spain & Canada & Belgium & iited Kingdom & Belgium & $\begin{array}{l}\text { Guer } \\
\text { Gue }\end{array}$ & Belgium & Jersey & Belgium \\
\hline 15 & $\begin{array}{c}\text { Canada } \\
\text { Cad }\end{array}$ & & Spain & Canada & Japan & Hong & Jer & & Gue & Ber \\
\hline 16 & Isle of Man & Sweden & & Spa & Belg & Jel & Nor & Jersey & Norway & Jersey \\
\hline 17 & Spain & Bermuda & Swed & Hong Kong & Hong Kong & Can & Swe & Hong Kong & & Sweden \\
\hline 18 & Jersey & ada & United Kingdom & Jar & Cyp & & Spain & & Swe & Canada \\
\hline 19 & Sweden & Cayman Islands & Cayman Islands & Cyprus & Spain & Norway & Canada & Canada & Cyprus & Norway \\
\hline 20 & Ireland & Hong Kong & & & Bermuda & Sweden & Republic of Korea & Cyprus & Hong Kong & Republic of Korea \\
\hline 21 & Netherlands Antilles I & Netherlands Antilles & & & Nor & Spain & Hong Kong & Republic of Korea & Republic of Korea & Hong Kong \\
\hline 22 & Norway & Norway & & & Caymar & Republic of Korea & $\mathrm{Cy}_{\mathrm{y}}$ & Bermuda & Bermuda & Slovenia \\
\hline 23 & Australia & Isle of Man & Isle & & & & & & enia & Bahrain, Kingdom of \\
\hline 24 & Cyprus & Mala & $\mathrm{F}$ & Republic of Korea & & & lands & Antilles & slands & \\
\hline 25 & Cayman Islands & Greece & Netherlands Antilles & Isle of & & Caym & Netherla & Islands & Antilles & \\
\hline 26 & Greece & Bahamas, The & Singapore & Singapore & Netherlands Antilles & & & Isle & & Cayma \\
\hline 27 & Bahrain, Kingdom of & Australia & Greece & Finland & Republic of Korea $\mathrm{I}$ & Netherlands Antilles & Greece & Chile & Iceland & Cy \\
\hline 28 & Malaysia & Cyprus & Hong Kong & Macao & Finland & Finland & Finland & Bahrain, Kingdon & ahrain, Kingdom of & rica \\
\hline $\begin{array}{l}29 \\
30\end{array}$ & $\begin{array}{c}\text { Portugal } \\
\text { Republic of Korea }\end{array}$ & $\begin{array}{l}\text { Chile } \\
\text { Republic of Korea }\end{array}$ & $\begin{array}{c}\text { Australia } \\
\text { Republic of Korea }\end{array}$ & $\begin{array}{l}\text { Netherlands Antilles } \\
\text { Czech Republic }\end{array}$ & 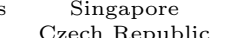 & $\begin{array}{l}\text { Slovak Republic } \\
\text { Hungary }\end{array}$ & $\begin{array}{l}\text { Czech Republic } \\
\text { Isle of Man }\end{array}$ & $\begin{array}{l}\text { Portugal } \\
\text { Macao }\end{array}$ & $\begin{array}{l}\text { Malaysia } \\
\text { Slovak Republic }\end{array}$ & $\begin{array}{l}\text { Lithuania } \\
\text { Iceland }\end{array}$ \\
\hline & & & & & & & & & & \\
\hline
\end{tabular}


Table 6: Weighted Hub Centrality

\begin{tabular}{|c|c|c|c|c|c|c|c|c|c|c|}
\hline ank & 20 & 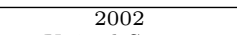 & & & 20 & & & & & \\
\hline $\begin{array}{l}1 \\
2\end{array}$ & $\begin{array}{l}\text { United States } \\
\text { United Kingdom }\end{array}$ & $\begin{array}{l}\text { United States } \\
\text { United Kingdom }\end{array}$ & $\begin{array}{l}\text { United States } \\
\text { United Kingdom }\end{array}$ & $\begin{array}{l}\text { United States } \\
\text { United Kingdom }\end{array}$ & $\begin{array}{l}\text { United States } \\
\text { United Kingdom }\end{array}$ & $\begin{array}{l}\text { United States } \\
\text { United Kingdom }\end{array}$ & $\begin{array}{l}\text { United States } \\
\text { United Kingdom }\end{array}$ & $\begin{array}{l}\text { United States } \\
\text { United Kingdom }\end{array}$ & $\begin{array}{l}\text { United States } \\
\text { United Kingdom }\end{array}$ & $\begin{array}{l}\text { United States } \\
\text { United Kingdom }\end{array}$ \\
\hline 3 & $\begin{array}{l}\text { Gited ingaomy } \\
\text { German }\end{array}$ & $\begin{array}{l}\text { Gnited Kingdom } \\
\text { Germany }\end{array}$ & Germany & Germany & Germany & Germany & Germany & Germany & Germany & Germany \\
\hline 4 & France & Netherlands & France & France & Japan & France & France & France & France & France \\
\hline 5 & Netherlands & France & Netherlands & Netherlands & France & Japan & Cayman Islands & Cayman Islands & Cayman Islands & Cayman Islands \\
\hline 6 & Japan & $\begin{array}{l}\text { Italy } \\
\text { Itan Islands }\end{array}$ & Italy & Cayman Islands & Cayman Islands & Cayman Islands & Japan & Netherlands & Netherlands & $\begin{array}{l}\text { Netherlands } \\
\text { Canada }\end{array}$ \\
\hline $\begin{array}{l}7 \\
8\end{array}$ & $\begin{array}{l}\text { Cayman Islands } \\
\text { Italy }\end{array}$ & $\begin{array}{c}\text { Cayman Islands } \\
\text { Japan }\end{array}$ & $\begin{array}{c}\text { Japan } \\
\text { Cayman Islands }\end{array}$ & $\begin{array}{l}\text { Italy } \\
\text { Japan }\end{array}$ & $\begin{array}{l}\text { Netherlands } \\
\text { Italy }\end{array}$ & $\begin{array}{l}\text { Netherlands } \\
\text { Italy }\end{array}$ & $\begin{array}{l}\text { Netherlands } \\
\text { Canada }\end{array}$ & $\begin{array}{l}\text { Italy } \\
\text { Japan }\end{array}$ & $\begin{array}{l}\text { Italy } \\
\text { xembourg }\end{array}$ & $\begin{array}{c}\text { Canada } \\
\text { Japan }\end{array}$ \\
\hline 9 & $\begin{array}{l}\text { Italy } \\
\text { Canada }\end{array}$ & $\begin{array}{l}\text { Japan } \\
\text { Canada }\end{array}$ & $\begin{array}{l}\text { Cayman Islands } \\
\text { Canada }\end{array}$ & $\begin{array}{l}\text { Japan } \\
\text { Canada }\end{array}$ & $\begin{array}{l}\text { Italy } \\
\text { Canada }\end{array}$ & $\begin{array}{l}\text { Italy } \\
\text { Canada }\end{array}$ & $\begin{array}{l}\text { Canada } \\
\text { Italy }\end{array}$ & $\begin{array}{l}\text { Japan } \\
\text { Luxembourg }\end{array}$ & $\begin{array}{l}\text { uxembourg } \\
\text { Canada }\end{array}$ & $\begin{array}{l}\text { Japan } \\
\text { Luxembourg }\end{array}$ \\
\hline 10 & Luxembourg & Luxembourg & Luxe & Luxembourg & Luxembourg & Luxembourg & Luxembourg & & & \\
\hline 11 & & & & & & & & & & \\
\hline 12 & & & & & & & & & & \\
\hline 13 & & & & & & & & & & \\
\hline 14 & & & & & & & & & & \\
\hline 15 & Sv & Bern & Ber & & & & & & & \\
\hline 16 & & & & & Sw & & & & & \\
\hline $\begin{array}{l}17 \\
18\end{array}$ & $\begin{array}{l}\text { Finland } \\
\text { Belgiumm }\end{array}$ & $\begin{array}{l}\text { Belgium } \\
\text { Finland }\end{array}$ & $\begin{array}{l}\text { Belg } \\
\text { Finl }\end{array}$ & m & $\begin{array}{l}\text { Republic } \\
\text { Belo }\end{array}$ & Republic & $\begin{array}{l}\text { Sweden } \\
\text { Bepublic of Korea }\end{array}$ & & & Republ \\
\hline $\begin{array}{l}18 \\
19\end{array}$ & $\begin{array}{l}\text { Deng } \\
\text { Hong }\end{array}$ & ublic & & Au & & & $\begin{array}{l}\text { Republic } \\
\text { Hong } 1\end{array}$ & & $\begin{array}{l}\text { Beri } \\
\text { public }\end{array}$ & \\
\hline 20 & Republ & & publi & & & & & & & \\
\hline 21 & Brazil & Netherland & & & & & & & & \\
\hline 22 & Austria & Hong & $\mathrm{M}$ & & & & & & & \\
\hline 23 & Netherlands Anti & $\mathrm{B}$ & Hon & & $\mathrm{Je}$ & & Ir & pub & & \\
\hline 24 & $\mathrm{Sin}_{1}$ & & & & & & Antilles & $\mathrm{Hc}$ & & \\
\hline 25 & & & & & & & $\mathrm{~N}$ & & & \\
\hline 26 & & & Antilles & & herl & erla & & & & \\
\hline 27 & & & & & & & lerat & & & \\
\hline 28 & Port & & & erl & & & & Ant & & rica \\
\hline 29 & Israel & & & & sia & - & & & & $\mathrm{R}$ \\
\hline 30 & sian Federation & isian Federation & Singapore & Singapore & Portugal & Singapore & Denmark & India & Netherlands Antilles & Singapore \\
\hline
\end{tabular}


Table 7: Weighted Authority Centrality

\begin{tabular}{|c|c|c|c|c|c|c|c|c|c|c|}
\hline Rank & 2001 & 2002 & 2003 & 2004 & 2005 & 2006 & 2007 & 2008 & 2009 & 2010 \\
\hline 1 & Japan & Japan & United States & United States & United States & United States & United States & Japan & United States & Japan \\
\hline 2 & United States & United States & $\begin{array}{l}\text { Japan } \\
\text { San }\end{array}$ & $\begin{array}{l}\text { Japan } \\
\text { Tan }\end{array}$ & Japan & United Kingdom & United Kingdom & United States & Japan & United States \\
\hline 3 & United Kingdom & United Kingdom & United Kingdom & United Kingdom & United Kingdom & Japan & Japan & United Kingdom & United Kingdom & United Kingdom \\
\hline 4 & Luxembourg & Luxembourg & Luxembourg & France & Luxembourg & Luxembourg & Luxembourg & Ireland & Luxembourg & Luxembourg \\
\hline 5 & $\begin{array}{l}\text { France } \\
\text { German }\end{array}$ & $\begin{array}{l}\text { France } \\
\text { raland }\end{array}$ & $\begin{array}{l}\text { France } \\
\text { rreland }\end{array}$ & $\begin{array}{l}\text { Luxembourg } \\
\text { Ireland }\end{array}$ & France & France & France & Luxembourg & Ireland & Ireland \\
\hline 6 & $\begin{array}{l}\text { Germany } \\
\text { Ireland }\end{array}$ & $\begin{array}{l}\text { Ireland } \\
\text { Germany }\end{array}$ & $\begin{array}{l}\text { Ireland } \\
\text { Netherlands }\end{array}$ & $\begin{array}{l}\text { Ireland } \\
\text { Netherlands }\end{array}$ & $\begin{array}{l}\text { Ireland } \\
\text { Netherlands }\end{array}$ & $\begin{array}{l}\text { Ireland } \\
\text { German }\end{array}$ & Ireland & France & France & France \\
\hline 7 & Ireland & Germany & Netherlands & Netherlands & Netherlands & Germany & Germany & Germany & Germany & Germany \\
\hline 8 & Netherlands & Netherlands & Germany & Germany & Germany & Netherlands & Netherlands & Netherlands & Netherlands & Netherlands \\
\hline 10 & Canada & $\begin{array}{l}\text { Italy } \\
\text { Switzerland }\end{array}$ & $\begin{array}{c}\text { Italy } \\
\text { Switzerland }\end{array}$ & $\begin{array}{l}\text { Italy } \\
\text { Switzerland }\end{array}$ & $\begin{array}{l}\text { Italy } \\
\text { Canada }\end{array}$ & Cana & Can & $\begin{array}{l}\text { Italy } \\
\text { Canada }\end{array}$ & $\begin{array}{l}\text { Italy } \\
\text { Canada }\end{array}$ & Canada \\
\hline 11 & Switzerland & Canada & Canada & Canada & Bermuda & Bermuda & Bermuda & Switzerland & Switzerland & $\begin{array}{l}\text { Bermuda } \\
\text { Switzerland }\end{array}$ \\
\hline 12 & Bermuda & Bermuda & Bermuda & Berr & Switzerland & Switzerland & Switzerland & Bermuda & Bermuda & 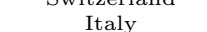 \\
\hline 13 & Belgium & Belgium & Spain & Spain & Spain & $\begin{array}{l}\text { Spain } \\
\text { Spain }\end{array}$ & Belgium & Belg & Norway & Norway \\
\hline 14 & Sweden & Spain & Belgium & Belgium & Belgium & Belgium & Spain & Norway & Belgium & Hong Kong \\
\hline 15 & Hong Kong & Hong Kong & Jersey & $\mathrm{Je}$ & & Jer & No1 & Spain & Hong Kong & Aus \\
\hline 16 & Spain & Jersey & Hong Kong & Hong Kong & Hong Kong & Norway & Hong Kong & Hon & Spain & $\mathrm{Be}$ \\
\hline 17 & Jersey & Sweden & Sweden & Sweden & Sweden & Hong Kong & Aus & Jersey & alia & Sw \\
\hline 18 & Australia & Norway & Norway & Norway & Norway & Sweden & $\mathrm{Je}$ & Aus & Sweden & Spain \\
\hline 19 & Norway & Australia & Australia & Australia & Australia & Australia & Sweden & Sw & Singapore & Jersey \\
\hline 20 & Austria & $\mathrm{Al}$ & & & $\mathrm{Au}$ & $\mathrm{Au}$ & $\mathrm{Al}_{2}$ & $\mathrm{Al}_{2}$ & Denmark & Denmark \\
\hline 21 & Denmark & Sing & De & & & $\mathrm{De}$ & & De & & \\
\hline 22 & Singapore & Cayman Islands & & & & & & & & \\
\hline 23 & Cayman Islands & Gue & Gue & $\mathrm{Gu}$ & & & & & & Gu \\
\hline 24 & Gues & Der & Cayma & & & & & & & ad \\
\hline 25 & & & & & Caym & lands & & & & frica \\
\hline 26 & South Africa & & & Cay & Po & & Repul & & & \\
\hline 27 & Isle of Man & South Africa & South Africa & South Africa & South Africa & Republic of Korea & Greece & Republic of Korea & South & \\
\hline 28 & Portugal & Isle of Man & Isle of Man & Greece & Gree & South Africa & Caymar & ica & Chile & Republic \\
\hline 29 & Argentina & Argentina & Greece & Republ & Erea & & 10 & Cayman Islands & epubl & \\
\hline & & eerlands Antilles & & & Isle of & & South Africa & & Isra & \\
\hline
\end{tabular}




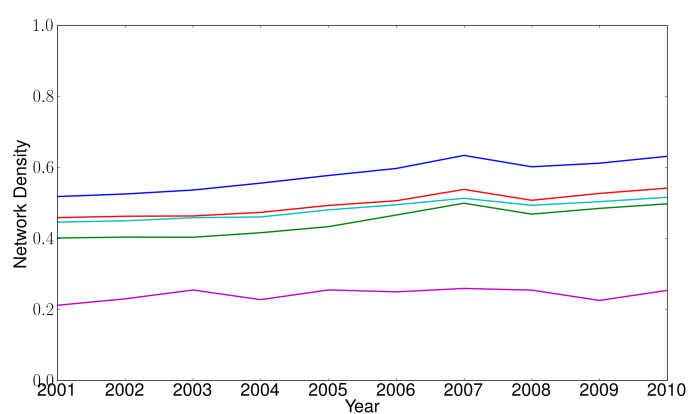

(a) Network density

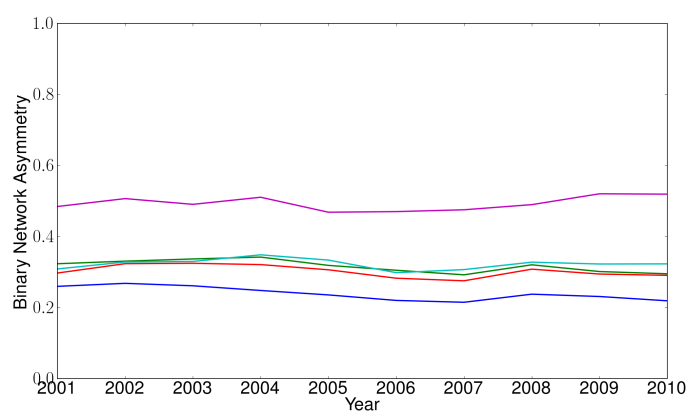

(c) Absolute binary network asymmetry

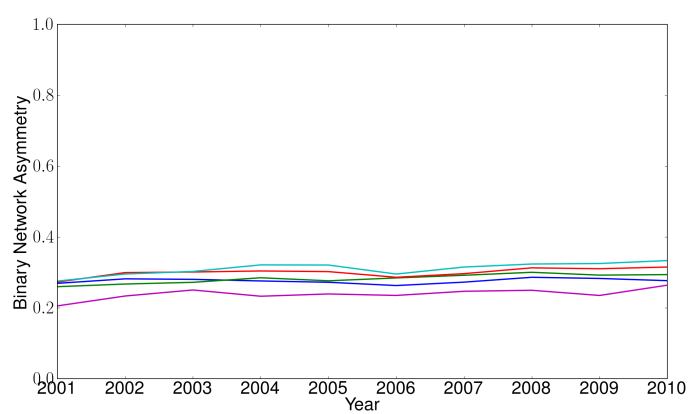

(e) Relative binary network asymmetry

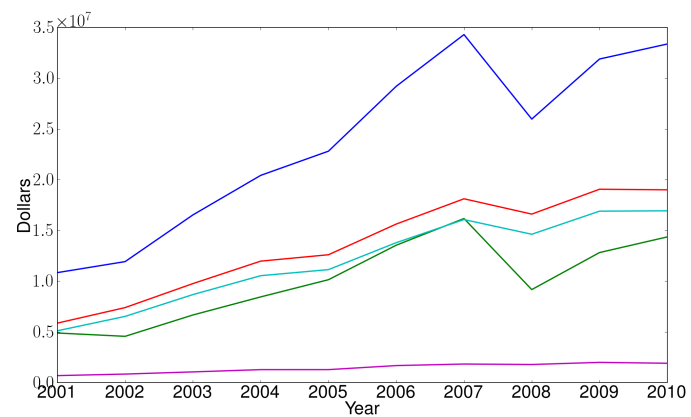

(b) Dollars of securities exchanged

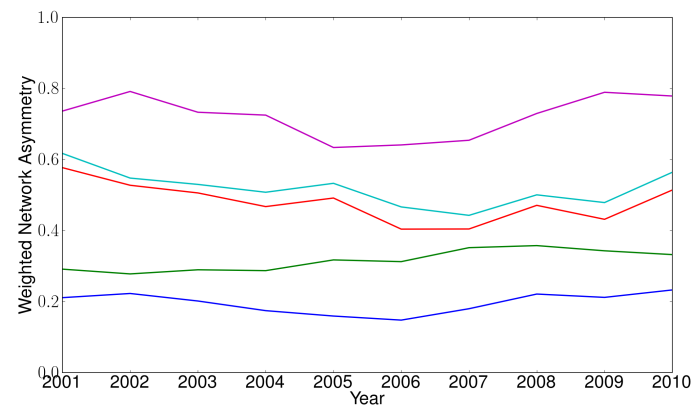

(d) Absolute weighted network asymmetry

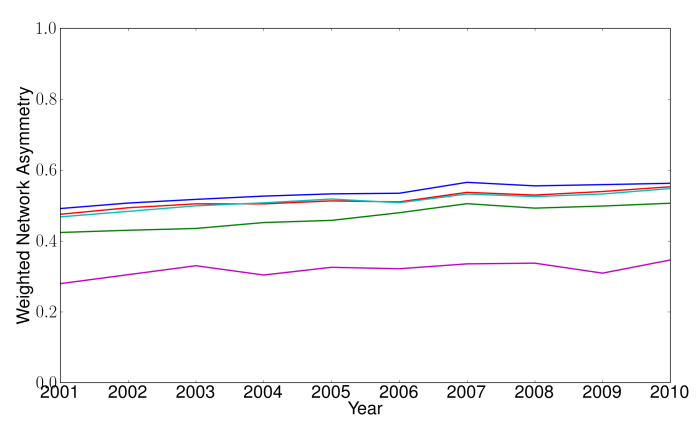

(f) Relative weighted network asymmetry

Figure 3: IFN Aggregate Behavior. Top-left: density. Top-Right: value of securities traded (in current dollars). Middle-Left: absolute binary network asymmetry index. Middle-Right: absolute weighted network asymmetry index. Bottom-Left: relative binary network asymmetry index. Bottom-Right: relative weighted network asymmetry index. Color lines refer to the five network layers. Blue: TPI. Green: ES. Red: TDS. Cyan: LTDS. Magenta: STDS. 


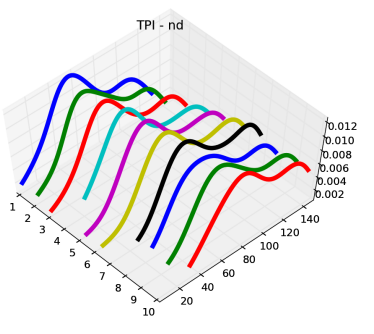

(a) TPI - \#creditors/debtors

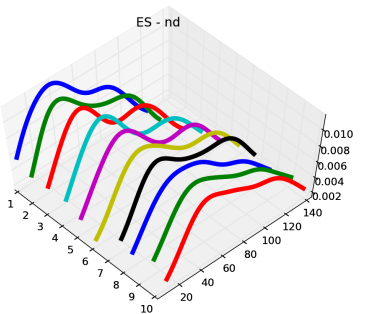

(d) ES - \#creditors/debtors

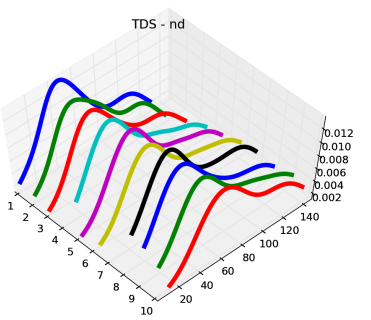

(g) TDS - \#creditors/debtors

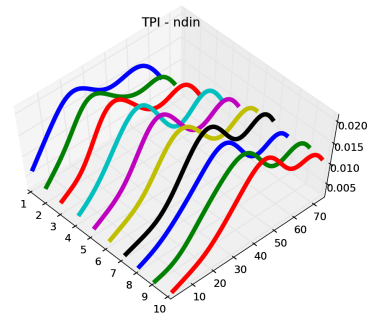

(b) TPI - \# debtors

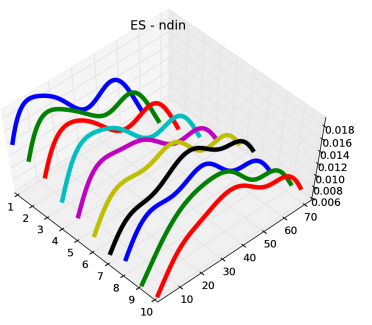

(e) ES - \# debtors

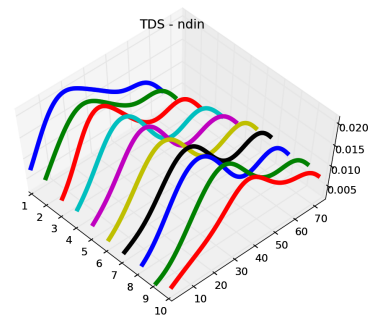

(h) TDS - \# debtors

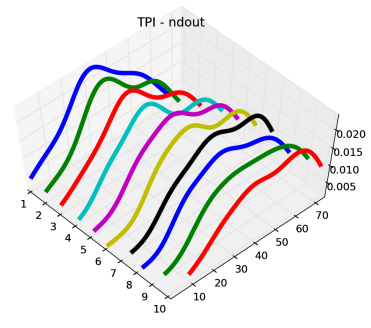

(c) TPI - \# creditors

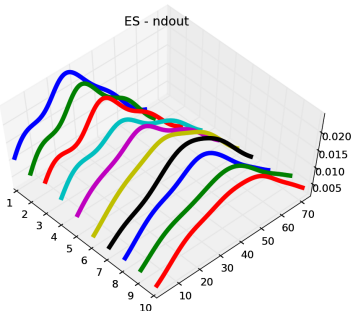

(f) ES - \# creditors

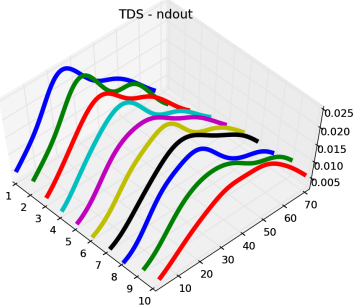

(i) TDS - \# creditors

Figure 4: Node degree distributions. TPI (top), ES (middle), and TDS (bottom). Years on the x-axis (e.g. 1 = year 2001), node degree on the y-axis, kernel density on the z-axis.

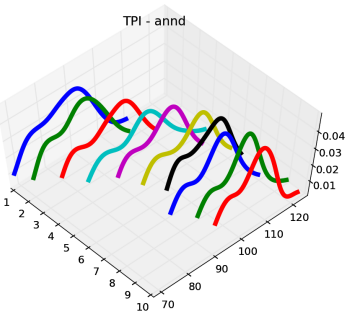

(a) ANND - TPI

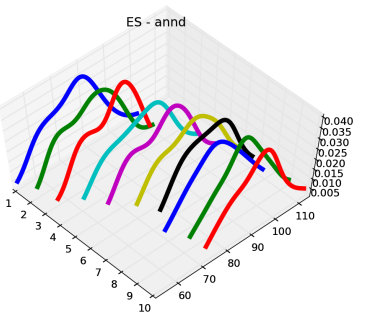

(b) ANND - ES

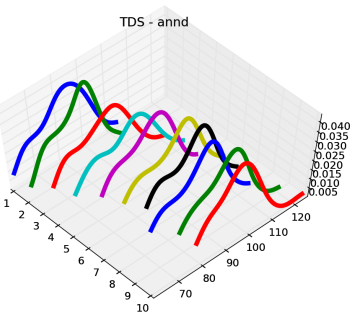

(c) ANND - TDS

Figure 5: Average nearest neighbor node degree distributions: years on the $\mathrm{x}$-axis (e.g. $1=$ year 2001), ANND on the y-axis, density on the z-axis. 


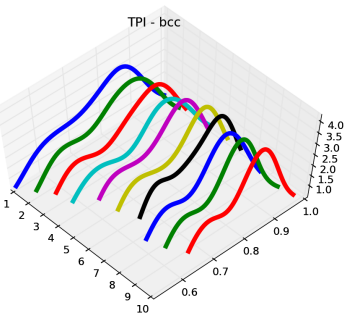

(a) Binary clustering - TPI

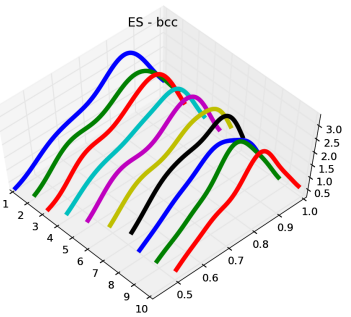

(b) Binary clustering - ES

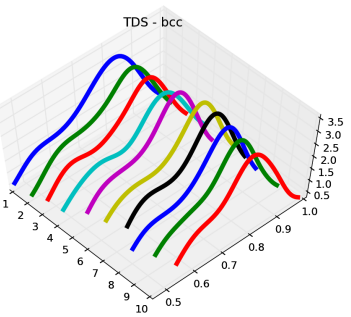

(c) Binary clustering - TDS

Figure 6: Binary clustering distributions. Years on the x-axis (e.g. 1 = year 2001). Binary clustering coefficients on the y-axis. Kernel density on the z-axis.

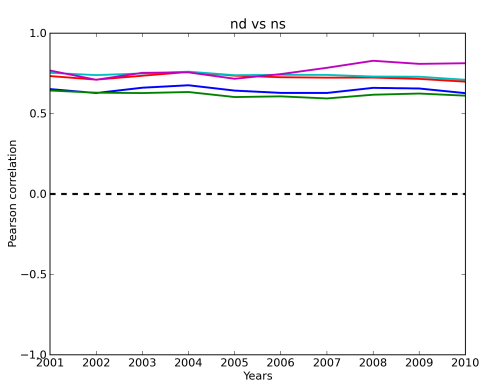

(a) ND vs NS

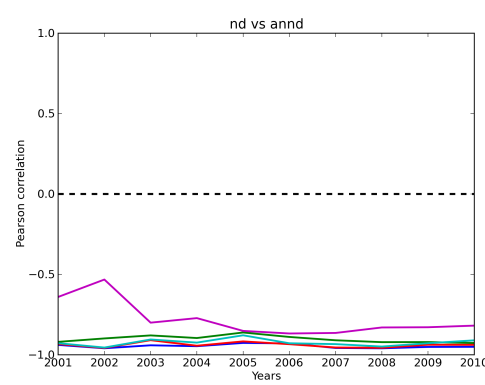

(b) ND vs ANND

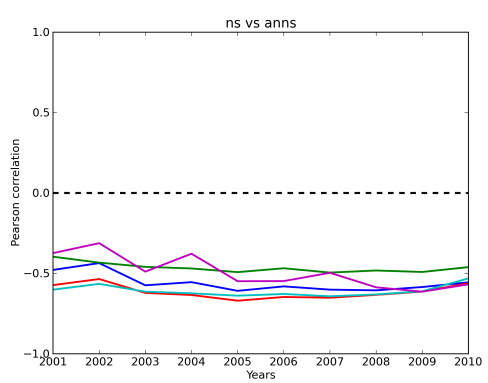

(c) NS vs ANNS

Figure 7: Correlations - 1: a) correlation between the number of partners and the total value of the securities exchanged; c) network disassortativity.

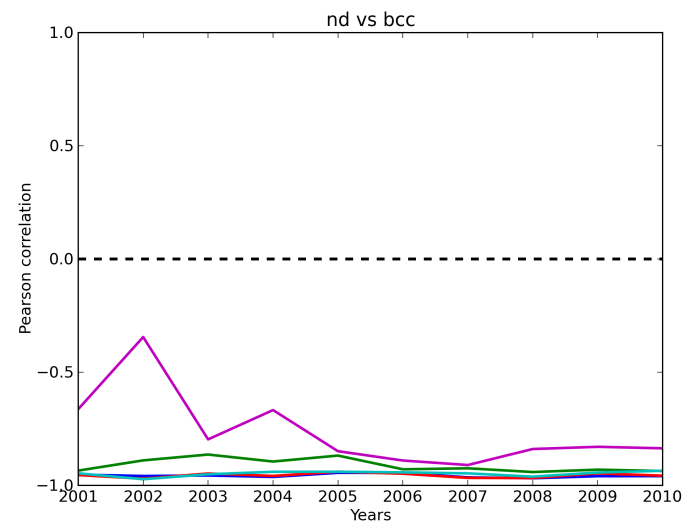

(a) $\mathrm{ND}$ vs $\mathrm{BCC}$

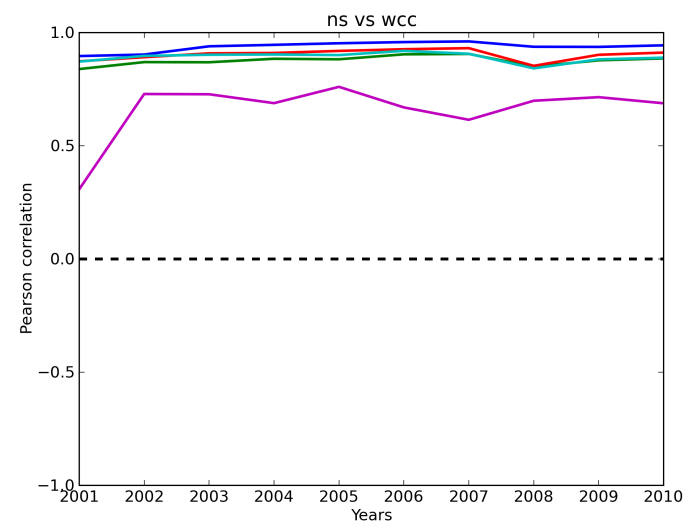

(b) NS vs WCC

Figure 8: Correlations - 2: Local Rich club evidence 


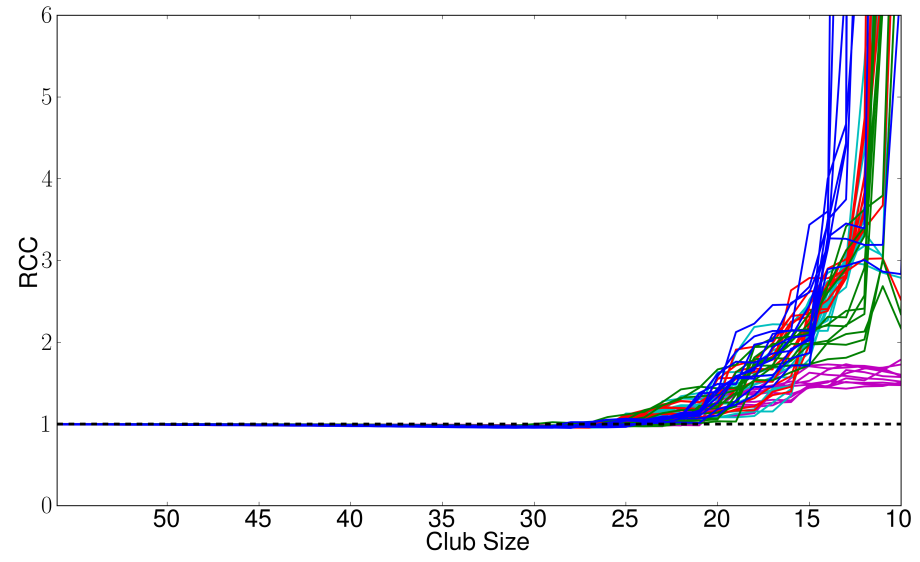

Figure 9: Rich-club behavior. Null Model: M1, see Appendix D (links are completely reshuffled so as to fully permute the weight matrix).

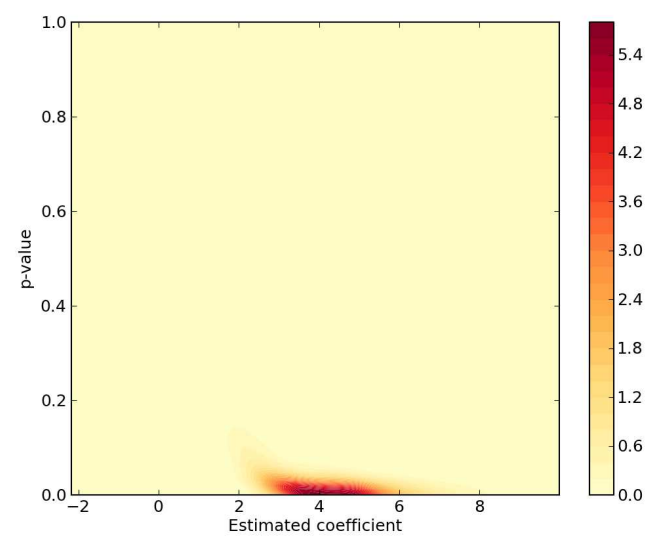

(a) NDin - TPI

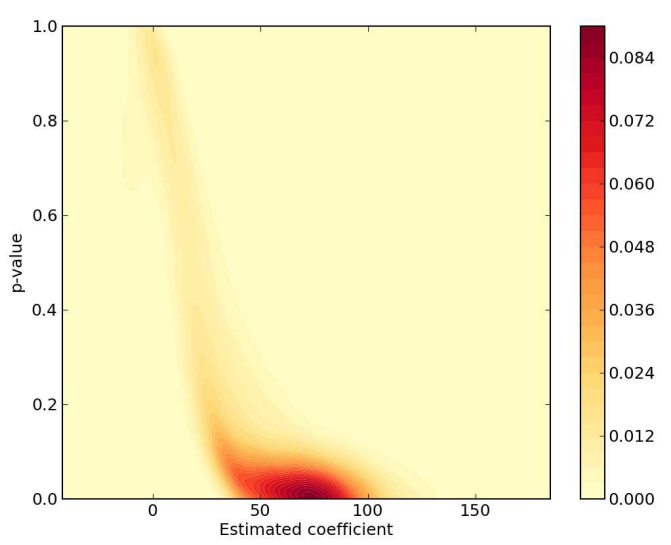

(b) $\log (\mathrm{WCC})-\mathrm{TPI}$

Figure 10: GMM regression analysis: Examples of significant regressors

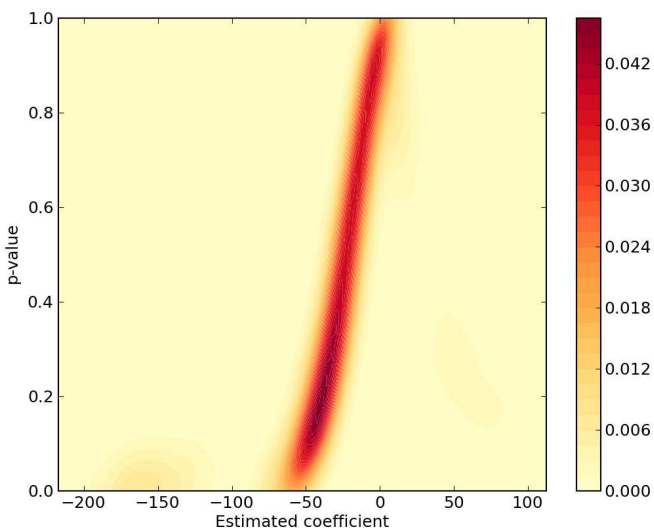

(a) $\log (\mathrm{BAC})-\mathrm{ES}$

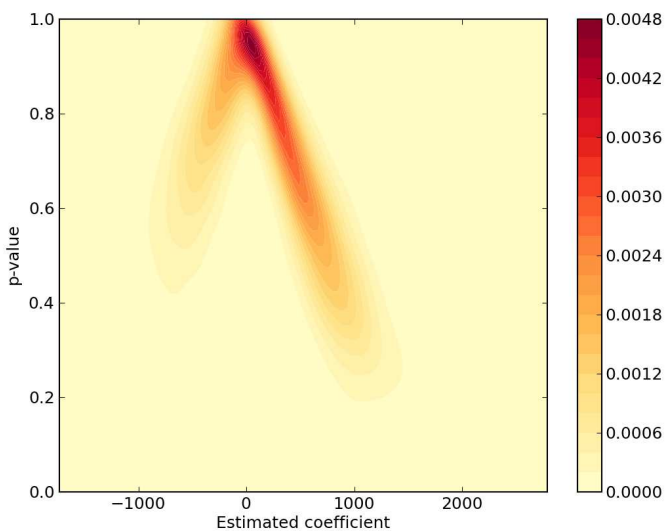

(b) WAC - TPI

Figure 11: GMM regression analysis: Examples of not significant regressors 